A\&L

ISSN 2709-0205

Vol 2 Issue 4 (2021)

https://doi.org/10.47855/ja19020-2021-4

\title{
Review
}

\section{Prospects of successful treatment of Parkinson's disease using apomorphine.}

\author{
Iryna N. Karaban, Tetyana V. Hasiuk, Nina V. Karasevych \\ D. F. Chebotarev Institute of Gerontology NAMS of Ukraine, Kyiv, Ukraine \\ https://doi.org/10.47855/jal9020-2021-4-1
}

Correspondence: karaban.pd@gmail.com

Received: 11.11.2021; Accepted: 29.11.2021; Published: 29.11.2021

\begin{abstract}
Optimising the treatment of idiopathic Parkinson's disease is a complex, multifaceted and continuous process that directly affects quality of life. The main position of this examination is the need for individualised therapy that provides optimal motor function with the least negative consequences. Apomorphine, a dopamine agonist used as rescue therapy for patients with motor fluctuations with a potentially positive effect on non-motor symptoms, is the only antiparkinsonian drug whose ability to control motor symptoms is equivalent to that of levodopa. Subcutaneous injection is the most effective and affordable way to correct dopaminergic insufficiency in Parkinson's disease. The data of multi-centre studies presented in the review confirm the high efficiency, adequate tolerability, and prospects of using apomorphine in the complex pathogenetic therapy of the disease. This review provides historical background and summarises the structure, mechanism of action, pharmacodynamics, indications, contraindications, and side effects of subcutaneous apomorphine injections in the advanced stages of Parkinson's disease.
\end{abstract}

Keywords: Parkinson's disease; apomorphine; pharmacokinetics; mechanism of action; clinical trials; indications: and contraindications

\section{Introduction with elements of historical review}

Parkinson's disease (PD) is a chronic neurodegenerative disease characterised by progressive loss of dopaminergic neurons in pars compacta black substance. The main symptoms of PD are: akinesia, rigidity, tremor and postural instability, in addition to which there are non-motor symptoms. Dopamine replacement therapy with levodopa and dopamine receptor agonists are the gold standard of treatment, which provides sufficient control of symptoms in the early stages of the disease. Nevertheless, after approximately 5 years of treatment, there is progressive depletion of dopamine expression caused by degeneration of dopaminergic neurons, which is clinically manifested by motor fluctuations and levodopainduced dyskinesias, which occur in almost $50 \%$ of cases and significantly impair the quality of life of patients [1]. Motor fluctuations occur due to loss and reduction of bioavailability of a single dose of levodopa; this phenomenon is known as wearing-off. Later, the phenomenon of "on/off" periods or sudden, unpredictable "off" episodes may occur [2]. Non-motor complications, such as anxiety, autonomic disorders, fatigue, mood swings, pain, or sensory symptoms, are a syndrome complex that often accompanies motor disorders [3]. The pathophysiological basis of clinical manifestations is considered to 
be pulsating stimulation of dopamine receptors induced by dopaminergic drugs, which occurs due to depletion of own dopamine reserves [5, 6]. Thus, the pulsating effect of oral administration of levodopa is due to the short half-life [4] and the unpredictable absorption process from the small intestine due to insufficient gastric emptying [7, 8]. Subsequently, sustained-release levodopa drugs and inhibitors of levodopa metabolism have been developed, as well as dopamine receptor agonists that provide a more stable level of levodopa plasma concentrations. It has been found that the advantages of dopamine receptor agonists are a longer half-life and their selectivity for dopamine D2 receptors, which are also thought to reduce the risk of dyskinesias [9]. Another common strategy to increase the duration of action of levodopa is based on the use of catechol-O-methyltransferase inhibitors (entacapone and tolcapone) and monoamine oxidase inhibitors (MAO-B).

The first attempts to use a parenteral drug with the effect of constant dopaminergic stimulation were made in the early 1980s.

A method of intravenous administration of levodopa or subcutaneous administration of dopamine agonist lisuride has been developed. However, despite its efficacy, the intravenous administration of levodopa was virtually impossible due to poor solubility, and the manufacturer withdrew lisuride during the already initiated manufacturing authorisation process with the FDA due to serious doubts about its clinical efficacy and safety [10,11].

After many years of work in this direction, the subcutaneous form of the dopamine receptor agonist apomorphine and levodopa/carbidopa intestinal gel (LCIG) began to be widely used for infusion therapy in PD to obtain the clinical effect of continuous dopaminergic stimulation.

It should be emphasised that apomorphine, as a natural product, has been used previously as an emetic, sedative, anticonvulsant, antipsychotic, as well as in alcohol dependence and sexual dysfunction [12]. Apomorphine was first proposed as a treatment for Parkinson's disease by Weil in 1844, but its properties in the treatment of Parkinson's disorders were not reported until the publication of Schwab et al. in 1951.

The effect was substantiated in 1967, the ability of apomorphine to reduce rigidity in experimental animals due to the structural similarity of the drug with dopamine was confirmed [12-14].

However, the widespread use of apomorphine in PD was prevented by its poor bioavailability when administered orally, the initial profile of side effects. Peripheral side effects of apomorphine, especially nausea, confirm its dopamine agonist activity, which has become easier to control with the advent of peripheral dopamine antagonists such as domperidone in Europe and trimethobenzamide in the United States [15, 18].

Nevertheless, the use of apomorphine for the PD treatment remained limited because levodopa became the cornerstone of the treatment, and other oral dopamine agonists were developed. Emphasis on the use of levodopa and dopamine agonists as monotherapy or in combination has distracted clinicians from apomorphine; that is why its use has been limited. It has only been used by small groups of neurologists who have convincingly justified its use as a rescue subcutaneous injection or continuous infusion for many years. This was especially true for Clinic of A. Lees in London, UK [16-18].

The uniqueness of the studies conducted by A. Lees have been confirmed by international clinical practice, which has noted emerging limitations in the oral administration of levodopa and dopamine agonists, especially in severe stages of PD.

Currently, the use of apomorphine in the treatment of clinical episodes with sudden "off" periods and "reduction of single-dose periods", when oral administration of the drug did not provide adequate clinical efficacy, is actively gaining recognition. But even this objective reality does not allow us to say that today apomorphine is a drug that is widely used in PD. Because the drug is mainly used in highly specialised centres, general neurologists often cannot realistically assess its high clinical efficacy [20-22]. This often raises practical questions about the efficacy of apomorphine compared with oral levodopa and dopamine agonists and other treatments for severe stages of PD (levodopa infusion and deep brain stimulation (DBS)) (Table 1). 
Comparison of different therapeutic approaches to the treatment of severe stages of PD

\begin{tabular}{|c|c|c|c|}
\hline $\begin{array}{l}\text { Type of } \\
\text { therapy }\end{array}$ & Indication & Benefits & Contraindication \\
\hline 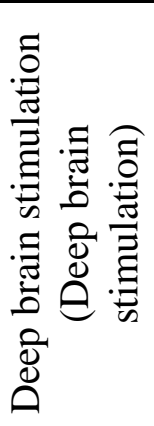 & $\begin{array}{l}\text { The best method for } \\
\text { dyskinesias }\end{array}$ & $\begin{array}{l}\text { - Reduces the need for } \\
\text { antiparkinsonian drugs } \\
\text { - Reversible (reversible) } \\
\text { - Non-ablative (non-ablative) } \\
\text { - Better with refractory tremor }\end{array}$ & $\begin{array}{l}\text { Invasive method of treatment } \\
\text { with surgical risk of } \\
\text { haemorrhage and infection }\end{array}$ \\
\hline 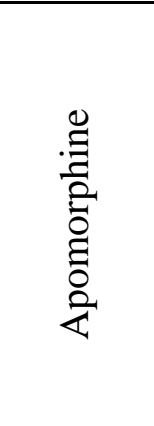 & $\begin{array}{l}\text { As a rescue aid in "off" } \\
\text { episodes, motor fluctuations }\end{array}$ & $\begin{array}{l}\text { - Moderately invasive method } \\
\text { - Parenteral route of } \\
\text { administration (important for } \\
\text { patients who cannot tolerate } \\
\text { oral therapy or have impaired } \\
\text { absorption) } \\
\text { - Penetrates rapidly through the } \\
\text { blood-brain barrier, does not } \\
\text { require additional transporters } \\
\text { and does not interact with } \\
\text { blood proteins }\end{array}$ & $\begin{array}{l}\text { - Frequent monitoring of blood } \\
\text { tests, ECG } \\
\text { - Requires the help of relatives } \\
\text { or guardians when setting } \\
\text { up the pump }\end{array}$ \\
\hline 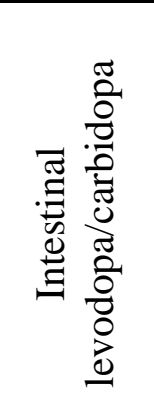 & $\begin{array}{l}\text { - Frequent "off" periods or } \\
\text { severe dyskinesias when } \\
\text { DBS or apomorphine are } \\
\text { contraindicated } \\
\text { - Infection or inoperability of } \\
\text { the patient } \\
\text { - Can reduce postural } \\
\text { disorders and, to some } \\
\text { extent, improve walking }\end{array}$ & $\begin{array}{l}\text { - A more physiological response } \\
\text { to dopamine and less } \\
\text { pulsating stimulation } \\
\text { - Less invasive than DBS } \\
\text { - Safe } \\
\text { - There are no age restrictions } \\
\text { - Primary and moderate } \\
\text { dementia is not a } \\
\text { contraindication }\end{array}$ & $\begin{array}{l}\text { - May worsen dyskinesia } \\
\text { - May cause anxiety, } \\
\text { depression, hallucinations, } \\
\text { confusion }\end{array}$ \\
\hline
\end{tabular}

Apomorphine Dopamine<smiles>CN1CCc2cccc3c2C1Cc1ccc(O)c(O)c1-3</smiles><smiles>NNCCc1ccc(O)c(O)c1</smiles>

Figure 1. Molecular structure of apomorphine and dopamine 
Apomorphine was the first dopamine agonist with potent antiparkinsonian action to be used in clinical practice decades before levodopa. Being a derivative of morphine, the drug was initially used as an emetic, expectorant, sedative, antipsychotic and anticonvulsant, and for the treatment of drug and alcohol dependence [23, 24]. It is now known that apomorphine is a highly lipophilic non-ergoline short-acting dopamine agonist that acts on types D1 and D2 dopamine receptors [24, 26]. Apomorphine was first synthesised in 1869 by Matthiessen and Wright [25], and Wail in 1884 recommended its use in PD. The first trials of the drug began in 1950. (Wenzel, Cotzias, Lees) [12, 25, 27]. In 1951, Schwab et al. [28] observed a decrease in rigidity and tremor in patients with PD as early as 5-10 minutes after subcutaneous administration of 0.5 to $1.0 \mathrm{mg}$ of apomorphine. These results were later confirmed by Cotzias et al. [24, 27]. Because oral administration of apomorphine in patients with PD requires a high dose to achieve the desired clinical response, severe peripheral responses were common side effects, which may include nausea, vomiting, postural hypotension, and renal impairment, resulting in increased urinary and creatinine levels [ 12]. To avoid these side effects, different routes of apomorphine administration have been studied. Subcutaneous administration was considered the most successful [23, 25, 29, 30, 32]. Apomorphine has been shown to have advantages over other dopamine agonists, such as lisuride, because it has fewer side effects and causes significant improvement in motor and non-motor symptoms such as hyperhidrosis, nocturia, urinary incontinence, fatigue, and mood disorders. The drug was well tolerated by patients with visual hallucinations, illusions and paranoid ideas, improved sleep disorders and restless legs syndrome, did not cause daytime drowsiness [33]. In 1988, a group of scientists led by A. Lees developed a mechanism for continuous subcutaneous apomorphine infusion, which was later recommended for patients with severe refractory "off" periods [17]. Although continuous treatment with apomorphine was first proposed by Stibe et al. [17] in 1988, subcutaneous drug injections were approved by the FDA for use in the treatment of "off" periods only in 2004 [26] and authorised under the title "Efficacy of apomorphine as a drug for rescue therapy in patients with PD."

Thus, treatment protocols for patients with PD were summarised and analysed, and standards for the treatment of Parkinson's disease were proposed. The overall goal of symptomatic treatment of PD is to control the symptoms of the disease while minimising the side effects of medications, including late complications in the form of motor fluctuations and dyskinesias. Levodopa is the most effective symptomatic drug for the PD treatment. Oral and transdermal dopamine agonists (DAs) also have dopaminergic benefits and may delay the development of motor complications when administered both as monotherapy and in combination with the minimum doses of levodopa required to control motor activity in the early stages of Parkinson's disease. After the development of motor fluctuations, therapeutic approaches include: increasing doses of levodopa or reducing the intervals between doses, adding catechol-O-methyltransferase and/or monoamine oxidase inhibitors (MAO-B) to block the breakdown of levodopa and dopamine, or adding DA in patients who have not yet taken this class of drugs in the absence of contraindications.

However, a significant proportion of patients inadequately controlled motor fluctuations remain, despite the use of several oral (or transdermal) drugs, with interruptions in the action of drugs, which is clinically manifested in "off" periods, as well as dyskinesias, including dystonia. The problem may also be exacerbated by bowel disorders, which often occur with the progression of PD, which, in turn, limits the absorption of drugs and the reliability of the effect of levodopa during the day. Difficulty swallowing is also a problem that aggravates the clinical symptoms in patients with PD and may affect the patient's ability to adhere to temporary oral medication.

\section{Pharmacology and mechanism of apomorphine}

Apomorphine is an aporphine derivative from the class of dibenzoquinolines, the molecular structure of which looks like a "rigid" form of dopamine (Fig. 1). This structural similarity imparts apomorphine to its dopaminergic activity, which is why it acts as a potent direct and broad-spectrum dopamine agonist, activating all dopamine D1-like (D1, D5) and D2-like (D2, D3, D4) receptors [34]. Its high affinity and similarity to dopamine receptors in combination with a reliable and rapid effect and onset of action after subcutaneous administration have made apomorphine a "key" and a tool in numerous laboratory studies of experimental models of PD. In normal rodents, the use of apomorphine causes 
stereotyped behaviour in rats, it restores motor deficiency in rodents with reserpine or haloperidol model of parkinsonism, and 6-OHDA- and MRTP-model rats and primates, reflecting its action as a central agonist [35].

It is widely believed that apomorphine is a typical dopamine agonist, but this is not entirely true given its multifaceted effects on dopamine and other receptors involved in the pathogenetic chain of clinical manifestations of PD. In fact, apomorphine is a molecule with a diverse range of pharmacological effects. Even given its interaction with dopamine receptors, it differs significantly from widely used oral dopamine agonists. For example, if the action of pramipexole and ropinirole is limited by D2-like receptors (D2 and D3), apomorphine interacts with both D1 receptors and classes D2 and with all major subtypes (D1, D2, D3, D4, D5), which may have important functional significance [34, 36].

The limited interaction of oral dopamine agonists with subtypes of dopamine receptors is often cited as the main reason why compounds such as ropinirole and pramipexole do not appear to have antiparkinsonian efficacy equivalent to levodopa monotherapy [37]. It has been shown that in the normal brain, levodopa acts on all types of dopamine receptors through the mechanism of conversion to dopamine (as well as endogenous neurotransmitter). Then, through the mechanism of conversion to dopamine, levodopa affects all types of dopamine receptors (as well as endogenous neurotransmitter) in the normal brain, which distinguishes levodopa from oral dopamine agonists, which have limited interaction with dopamine receptors, with less D1 receptor activation. The D1 receptor, in particular its major conduction pathways, can be considered to be directly related to the striatum, which may be attributed to the initiation of dyskinesias [38, 39], but in reality, this hypothesis has never been proven. Thus, in preclinical studies, the introduction of D1 agonists did not lead to greater induction of dyskinesias or their expression compared with drugs - D2-receptor agonists. Rather, it appears to be an advantage stimulating D1 receptors, which causes a reduction in motor deficits in model animals with Parkinson's syndrome and in people with PD [40, 41]. Activation of D1 receptors may also be useful in the treatment of non-motor symptoms of PD, such as bladder hyperreflexia, which has been demonstrated in both experimental models and clinical trials in patients with PD [42, 43].

It is now known that dopamine receptors are located in many parts of the brain, not just in the basal ganglia. Activation of cortical and limbic areas in response to dopamine agonists provokes some side effects similar to those seen with dopaminergic replacement therapy in patients with PD, including impulse-control disorder (ICD) and visual hallucinations. Therefore, such a broad dopamine-like action of apomorphine can be considered as a disadvantage. For example, it has been suggested that ICD may be associated with the activation of D3 receptors in the limbic areas [44].

Indeed, it has been shown that a relatively high proportion of patients with ICD treated with pramipexole, ropinirole and rotigotine show a direct correlation with the selectivity of these drugs to D3 receptors compared to D2 receptors [44]. The apomorphine has a lower ratio of D3: D2 than pramipexole and ropinirole [36], which may be of clinical significance, although it is currently unknown whether the incidence of ICD was actually lower with apomorphine compared to other dopamine agonists.

Recovery of dopamine with levodopa may not be the only reason that levodopa is highly effective in PD. Some of the dopamine formed from levodopa, in turn, is converted to norepinephrine

(which is known to be deficient in PD). In addition, dopamine derived from levodopa accumulates in serotonergic neurons and can displace 5-HT. In this regard, apomorphine also has a multifaceted pharmacological effect, as it has an affinity for serotonin receptors (5HT1A, 5HT2A, 5HT2B and 5HT2C) and $\alpha$-adrenoceptors $(\alpha 1 \mathrm{~B}, \alpha 1 \mathrm{D}, \alpha 2 \mathrm{~A}, \alpha 2 \mathrm{~B}$ and $\alpha 2 \mathrm{C})$ [34]. However, this fact is the main reason for reservations about the use of oral agonists ropinirole and pramipexole, which usually have a more limited pharmacological profile.

Thus, almost all DAs show selectivity for one specific receptor, which mediates their main pharmacological and clinical activity. However, very few of them are specific in their receptor interactions, and most of them show targeted efficacy, which is a potential cause of unwanted side effects. In particular, this can be attributed to such DAs as ergot derivatives (bromocriptine, pergolide, cabergoline), which, despite their high efficacy, were withdrawn due to rare but very serious complications, such as the occurrence of pulmonary fibrosis and cardiac fibrous valvulopathy, due to a direct effect on the activity of 5-HT2B receptors $[45,46]$. Moreover, this has been a major reason for the development of non-ergoline 
drugs such as ropinirole and pramipexole, and their activity has been directed at isolated effects on only some subtypes of dopamine receptors.

Consideration of the multimodal pharmacological profile of apomorphine for all subtypes of dopamine receptors showed its high therapeutic efficacy compared to the profile of possible side effects. For example, apomorphine, interacting with 5-HT2B receptors, is far less active than ergot derivatives (at least in vitro) [34]. After analysing the database of DAs' side effects, the FDA did not confirm similar signs for apomorphine [47]. It has been suggested that apomorphine relatively rarely causes visual hallucinations due to the putative potential mechanism of its interaction with the activity of 5-HT2 receptors [48-51].

It has also been shown that apomorphine binds to pre- and postsynaptic dopamine receptors and gives a therapeutic effect by directly stimulating postsynaptic D2 receptors in the striatum, which leads to the activation of direct and inactivation of indirect striatopallidal bonds [ 51-53].

The motor response to a single subcutaneous apomorphine injection occurs similarly to the response to levodopa, but with a faster onset (approximately $4-12 \mathrm{~min}$ ), with an average duration of effect of 45-60 $\mathrm{min}[51,57]$. In light of these therapeutic effects, apomorphine has become one of the prototypes of "rescue care" in PD in cases of unpredictable "off" periods that occur in patients with severe stages of the disease with poorly controlled motor fluctuations.

In addition, apomorphine does not compete for metabolic pathways with levodopa and, unlike levodopa, does not require an active transport mechanism to achieve an effect on the central nervous system $[52,53,58,62,63]$. The drug absorption depends on temperature, and its best absorption is achieved when injected into the subcutaneous tissue of the anterior abdominal wall.

Apomorphine does not interact with cytochrome P450 inhibitors, and the cytochrome P450 system itself does not interfere with drug metabolism.

When administered subcutaneously, apomorphine is rapidly absorbed and readily crosses the blood-brain barrier due to its high lipophilicity. The peak plasma concentration is achieved in 10-20 min after subcutaneous administration, and the maximum concentration in cerebrospinal fluid is achieved in $30 \mathrm{~min}$. On average, the apomorphine's clinical effect starts in 7-17 minutes after subcutaneous injection. The half-life of apomorphine subcutaneous administration from blood plasma lasts about 30 minutes, and the concentration of the drug in plasma remains quite stable [61, 62]. Factors such as the site of injection, depth of injection, skin temperature and possibly the thickness and quality of subcutaneous tissue may alter the absorption phase of the administered drug, which may lead to variability in clinical effect in different patients; however, the intra-individual reproducibility of the effect remains very high.

Age, sex, disease duration, levodopa dosage, or long-term apomorphine therapy do not appear to play a leading role in drug clearance [54, 59, 60, 61].

\section{Efficacy of apomorphine according to clinical studies}

Clinical studies in recent decades have probably established the efficacy of apomorphine in reducing the time of "off" periods that occur in patients with PD on the background of levodopa therapy. Like levodopa, apomorphine was first approved for clinical use when drug marketing authorisation and clinical trial design requirements were less stringent than they are today. Apomorphine, as an antiparkinsonian drug, had been used in Europe long before the results of randomised controlled trials, which shed light on the results of evaluating the efficacy of intermittent apomorphine injections in patients with PD, were received.

Table 2 summarises the main data from double-blind trials evaluating the efficacy of intermittent apomorphine injections for the treatment of patients with PD. The majority of data from randomised controlled trials were collected for the drug's marketing authorisation in the United States. Taken together, the studies provide a compelling evidence base for the efficacy of intermittent injections, providing rapid relief in sudden off episodes in patients with PD. 
Table 2

The results of double-blind studies of the efficacy of intermittent apomorphine injections for the PD treatment

\begin{tabular}{|c|c|c|c|}
\hline Research & Design & $\begin{array}{l}\text { Injectio } \\
\text { n dose }\end{array}$ & Conclusions on efficacy \\
\hline $\begin{array}{l}\text { Cotzias et al., } \\
1970\end{array}$ & $\begin{array}{l}\text { A double-blind, } \\
\text { placebo-controlled, } \\
\text { crossover study. } 6 \text { of } 15 \\
\text { patients had PD }\end{array}$ & $0.25-2 \mathrm{mg}$ & $\begin{array}{l}\text { Rapid improvement ( } \geq 20 \% \text { ) on neurological examination was } \\
\text { observed in } 5 \text { of } 6 \text { patients with PD. }\end{array}$ \\
\hline $\begin{array}{l}\text { Van Laar et } \\
\text { al., } 1993\end{array}$ & $\begin{array}{l}\text { randomised, double- } \\
\text { blind, placebo- } \\
\text { controlled, crossover } \\
\text { study. } \mathrm{N}=5\end{array}$ & $\begin{array}{l}\text { On } \\
\text { average, } \\
2.7 \mathrm{mg}\end{array}$ & $\begin{array}{l}\text { A significant positive effect of apomorphine compared to } \\
\text { placebo was assessed using the CPDS scale }(p=0.001) \text {. Effect } \\
\text { delay: } 7.3 \mathrm{~min} \text { Response time: } 96 \mathrm{~min}\end{array}$ \\
\hline $\begin{array}{l}\text { Ostergaard et } \\
\text { to the., } \\
1995\end{array}$ & $\begin{array}{l}\text { Double-blind, } \\
\text { placebo-controlled } \\
\text { study. } \mathrm{N}=22\end{array}$ & $\begin{array}{l}\text { On } \\
\text { average, } \\
3.4 \mathrm{mg}\end{array}$ & $\begin{array}{l}\text { The average daily duration of the "off" period decreased by } 58 \% \\
\text { compared with placebo }(\mathrm{p}<0.001) \text {. } \\
\text { The severity of the "off" period was also significantly reduced }\end{array}$ \\
\hline $\begin{array}{l}\text { Merello et al., } \\
1997\end{array}$ & $\begin{array}{l}\text { Double-blind cross- } \\
\text { over study using the } \\
\text { active drug (dispersed } \\
\text { levodopa/benserazide). } \\
\mathrm{N}=12\end{array}$ & $3 \mathrm{mg}$ & $\begin{array}{l}\text { Average } \pm \text { SE of he effect delay (estimated using a modified } \\
\text { WRS scale) was } 8.08 \pm 3.00 \text { min for apomorphine versus } 26.8 \pm \\
12.7 \text { min for dispersed levodopa. } \\
\text { Average } \pm \text { SE of effect duration was } 56.6 \pm 13.6 \text { min for } \\
\text { apomorphine against } 97.0 \pm 35.8 \text { min for dispersed levodopa }\end{array}$ \\
\hline $\begin{array}{l}\text { Dewey et al., } \\
2001\end{array}$ & $\begin{array}{l}\text { randomised, double- } \\
\text { blind, placebo- } \\
\text { controlled, two-phase } \\
\text { study. } \mathrm{N}=29\end{array}$ & $\begin{array}{l}\text { On } \\
\text { average, } \\
5.4 \mathrm{mg}\end{array}$ & $\begin{array}{l}\text { Phase } 1 \text {. Mean motor activity on the UPDRS scale decreased by } \\
62 \% \text { with apomorphine versus } 1 \% \text { with placebo. Phase } 2 \text {. } \\
\text { Apomorphine interrupted } 95 \% \text { of "off" periods vs. } 23 \% \text { when } \\
\text { taking placebo }\end{array}$ \\
\hline $\begin{array}{l}\text { Pfeiffer et al., } \\
2007\end{array}$ & $\begin{array}{l}\text { A randomised, double- } \\
\text { blind, placebo- } \\
\text { controlled study in four } \\
\text { groups. } \mathrm{N}=62\end{array}$ & $\begin{array}{l}\text { UED } \\
\text { or UED } \\
2 \mathrm{mg}\end{array}$ & $\begin{array}{l}\text { Significantly greater improvement in mean motor activity on the } \\
\text { UPDRS scale was observed in the pooled apomorphine groups } \\
\text { than in the pooled placebo groups } 20 \text { minutes after administration } \\
(-24.2 \text { vs. }-7.4 ; p<0.0001) \text {. The difference was also significant after } \\
10 \text { min }(p<0.0001) \text {. Significant difference compared to placebo on } \\
\text { the WSST scale after } 7.5 \mathrm{~min}(\mathrm{p}=0.02)\end{array}$ \\
\hline $\begin{array}{l}\text { Pahwa et al., } \\
2007\end{array}$ & $\begin{array}{l}\text { Dose escalation studies } \\
\text { with a randomised, } \\
\text { double-blind, placebo- } \\
\text { controlled, cross- } \\
\text { sectional single dose } \\
\text { assessment. } \mathrm{N}=56\end{array}$ & $4-10 \mathrm{mg}$ & $\begin{array}{l}\text { Probable improvement in motor activity on the UPDRS scale } \\
\text { when taking } 4 \mathrm{mg} \text { of apomorphine compared with placebo after } \\
20(p=0.0002), 40(p<0.0001) \text { and } 90 \mathrm{~min}(\mathrm{p}=0.0229) \text {. A significant } \\
\text { dose-dependent effect was observed after } 20(p<0.0001), 40 \text { ( } p \\
<0.0001) \text { and } 90 \mathrm{~min}(\mathrm{p}=0.0049) \text { after administration }\end{array}$ \\
\hline $\begin{array}{l}\text { Stacy and } \\
\text { Silver, } \\
2008\end{array}$ & $\begin{array}{l}\text { A double-blind, } \\
\text { placebo-controlled, } \\
\text { crossover study. } \mathrm{N}=17\end{array}$ & $\begin{array}{l}\text { The } \\
\text { average } \\
\text { is } 3.91 \mathrm{mg}\end{array}$ & $\begin{array}{l}\text { Probable decrease in motor activity on the UPDRS scale after } 20 \\
\text { min on average by } 20.0 \text { points when using apomorphine against } \\
3.0 \text { - placebo }(\mathrm{p}<0.0001)\end{array}$ \\
\hline
\end{tabular}

Notes: CPDS - Columbia University Parkinson's disease scale; SE - standard error; UED - usually effective dose; UPDRS - Unified Parkinson's Disease Rating Scale; WRS - Webster rating scale; WSST - Webster Step Second-Test. 


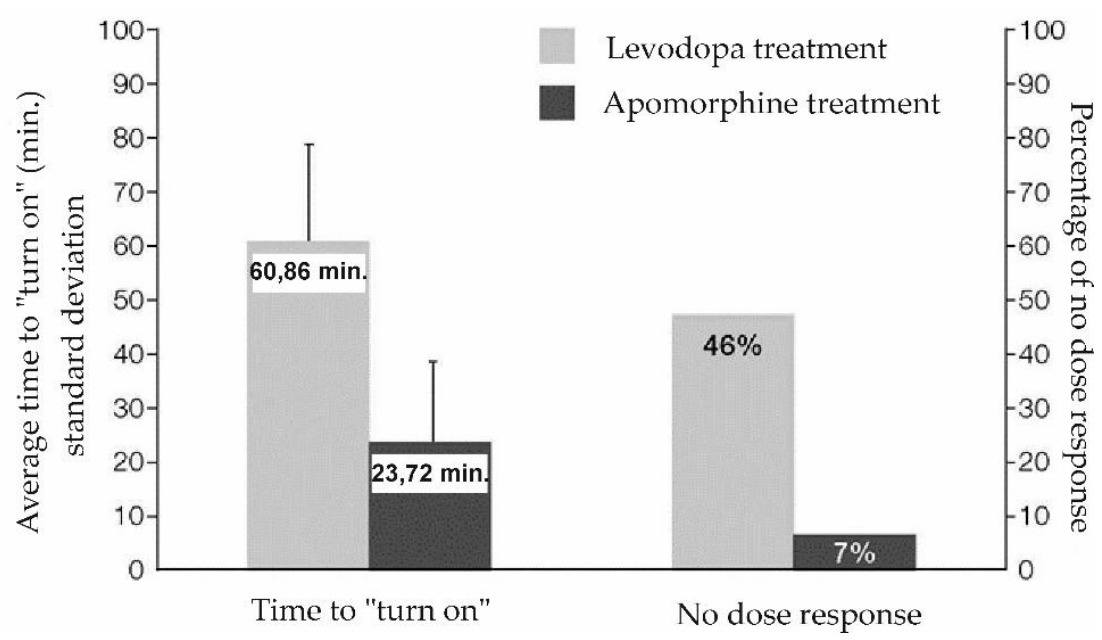

Figure 2. Time to "turn on" and the percentage of no response to levodopa and apomorphine in the study AM-IMPAKT $(n=88)$. Patients recorded in the diary every 5 minutes the time before passing to "on" period after taking a single dose of levodopa or apomorphine marked "yes" or "no" before the start of "on" period $\leq$ 60 minutes. A value of 100 was adopted for patients who did not report passing "on" period of a dose of levodopa. Subcutaneous apomorphine injections have been shown to be more effective in restoring "on" period than levodopa monotherapy $(n=88)$.

Several open-label studies on the use of intermittent apomorphine injections, usually conducted in separate centres, have provided early evidence of the efficacy of intermittent apomorphine injections (single doses ranging from 2 to $5 \mathrm{mg}$ ) to provide rapid and immediate treatment of "off" episodes. When apomorphine was administered "as needed", the mean reduction in daily off time was in the range of 2.6-4.0 h. Relief of symptoms was rapid (usually after $10 \mathrm{~min}$ ), and the duration of the effect was reported to be at least one hour. It should be noted that some of these studies reported that patients experienced better control of their symptoms and gained confidence in the actual ability to emerge from "off" episodes [64-66].

More recently, the results of an open-label study AM-IMPAKT were published [67]. The AM-IMPAKT study was a phase IV multicentre study to evaluate the effect of apomorphine injection in patients with prolonged morning akinesia due to delayed or inadequate passing to the "on" period after the first morning dose of levodopa. Morning akinesia was considered valid if the patient's "on" time on levodopa exceeded 45 minutes with a constant daily dose of levodopa for at least 3 days and one week from baseline. It should be noted that patients in this open-label study had a longer time to "turn on" on the morning dose of levodopa, which averaged 1 hour, and the frequency of "inefficacious single doses" of levodopa during the day was high. The reduction in "on" time (mean reduction by $37.14 \mathrm{~min}$ ) and increased response reliability (frequency of inefficacious morning doses of levodopa was $46 \%$ vs. $7 \%$ with apomorphine) was clinically significant, as evidenced by a significant improvement, marked by patients on the scales of quality of life and e Clinical Global Impression (CGI) (Fig. 2).

\section{Efficacy of intermittent apomorphine injections}

The first double-blind studies, in which intermittent subcutaneous apomorphine injection was used in PD, were conducted in 1970 by Cotzias et al., and then in 1988 by Stibe et al., in which the drug was used for rescue therapy in the "off" periods [68]. Published studies of the efficacy of intermittent apomorphine injections in the early stages of PD were openly uncontrolled and had a small sample size. The most striking result of these studies was the reduction of the mean "off" period to $44 \%$, while the average dosage of levodopa remained largely unchanged [69-76]. Dyskinesias were not specifically considered in these studies. Later, Hughes et al. published the results of a study of 71 patients. Patients received intermittent apomorphine injections up to 10 times a day or more, due to which they had to change the tactics of intermittent apomorphine injections to a continuous drug infusion by the means of a pump [71]. It was shown that in 49 patients who received intermittent apomorphine injections, a reduction in the "off" period was achieved by 50\%. After 1 year of treatment, about $80 \%$ of patients continued to report the efficacy of apomorphine therapy. The average daily dose of apomorphine increased by $24 \%$ for 1 year of use, while the dose of levodopa was reduced by $5 \%$. 
Other studies have shown similar results, indicating a lack of tolerance to subcutaneous administration of apomorphine, and its efficacy is equally likely in patients at different stages of PD. One of the first double-blind placebo-controlled studies was conducted in 1995 by Oestergaardon et al. [73]. After domperidone premedication, 22 patients were administered a dose of apomorphine at intervals of $120 \mathrm{~min}$; the subcutaneous dose amounted to =1.6; 3.2; 4.8 and $6.4 \mathrm{mg}$. Doses of placebo were administered randomly during treatment.

The second phase of this study was to evaluate the dosage of the drug followed by 8-day placebo-controlled cross-therapy, including the apomorphine administration for 4 days and placebo for 4 days. In the third phase of the study, patients were evaluated during an 8-week open-label outpatient treatment period. There was a reduction in the "off" period by more than $50 \%$ when using apomorphine at an average dose of $3.4 \mathrm{mg}$. Twelve patients reported improvement "strongly" or "very strongly" in their assessment of the Clinical Global Impression Scale. In addition, there was a decrease in the severity of concomitant dysphonia and painful dystonia [77].

A number of controlled studies have been performed in the United States to evaluate the efficacy and tolerability of apomorphine. Thus, the Apomorphine National Institute of Health Study studied 28 patients with PD, which were divided into four groups: patients with "single dose depletion", unpredictable fluctuations of the "on/off" period, stable response to levodopa and those who have not previously taken levodopa. In all groups, there was a significant improvement in motor assessment by $35-77 \%$.

The APO202 study was the main randomised prospective double-blind placebo-controlled study. 29 patients were randomised, of which 20 were in the active treatment group and 9 in the placebo group. The length of the "off" period was assessed using the patient's diary and UPDRS scale. There was a significantly greater reduction in the "off" period $(\mathrm{p}<0.001)$ in the apomorphine group $(95.0 \pm 2.4 \%)$ compared with the placebo group ( $23.0 \pm 0.4 \%)$. The average effective dose of apomorphine was $5.4 \mathrm{mg}$. This effect was comparable to the effect of levodopa, but the period with dyskinesias increased, and the severity of dyskinesias did not change. The study was completed by 17 patients in the apomorphine group and 8 patients in the placebo group. Yawning, drowsiness, and nausea were more common in the apomorphine group, but no other differences in side effect profiles were found [76].

The long-term efficacy of apomorphine as a rescue drug was evaluated in study APO302: 62 patients who had at least 3 months of apomorphine treatment experience received their usual"immediate" injection, but used $2 \mathrm{mg}$ more than the usual effective dose or placebo. The primary end point of the study was to obtain results on the possible improvement of the motor part of the UPDRS scale. It was shown that the higher efficacy of apomorphine compared with placebo was determined as an improvement in the motor part of the UPDRS scale and was observed after $10 \mathrm{~min}$ (-19.9 vs. -5.6 with placebo, $\mathrm{p}<0.001)$ and $20 \mathrm{~min}(-24.2$ vs. -7.4 with placebo, $\mathrm{p}<0.001)$ [78].

In the APO301 study, which evaluated the long-term efficacy of apomorphine therapy in 17 patients over 4-51 months who received their usual effective dose of apomorphine (mean dose $4 \mathrm{mg}$ ) or placebo, the maximum improvement in motor scores on the UPDRS scale was 21.3 points. 20 min after injection [79].

In the APO303 study, 56 patients who had not previously received apomorphine were randomised to evaluate the efficacy of apomorphine or placebo at doses up to $10 \mathrm{mg}$. It was shown that the UPDRS score improved by 11.3 points in $20 \mathrm{~min}(\mathrm{p}=0.0002)$ in the main group and by 13.4 points in $40 \mathrm{~min}$ in the placebo group $(\mathrm{p}=0.0001)[80,81]$.

These key studies contributed to the approval of apomorphine in the US FDA in 2004 entitled "The use of intermittent subcutaneous apomorphine injections as a treatment for sudden "off" periods in patients with PD.

Preliminary results of the Phase IV multicentre open-label study (Apokyn for Motor IMProvement of Morning Akinesia Trial) in 37 patients with morning akinesia due to delayed onset of levodopa revealed that apomorphine injection was a highly reliable and effective therapy in $96 \%$ of patients time to the "on" period was up to 40 minutes [82]. This study also emphasised that non-oral routes of delivery of dopaminergic drugs, such as apomorphine injections, are a real possibility for adequate treatment of PD with a delayed on time on the dose of levodopa, which is associated with gastrointestinal dysfunction, which is usually observed in patients with PD. 
The TOLEDO study was the first double-blind randomised clinical trial of subcutaneous apomorphine infusion in patients with PD [87]. The study included patients with a disease duration of more than 3 years, accompanied by motor fluctuations, which were poorly controlled by oral or transdermal antiparkinsonian drugs, and in which patients received at least 4 daily doses of levodopa.

The 12-week study involved subcutaneous apomorphine infusion or placebo, followed by openlabel 64-week treatment with apomorphine. 107 patients were randomised, most of whom were hospitalised during the apomorphine titration phase. The dose of apomorphine was adjusted during the first 4 weeks followed by an 8-week maintenance period (dose of apomorphine: 3-8 mg/year). It has been shown that subcutaneous apomorphine infusion reduced the duration of the "off" period (-2.47 vs. -0.58 $\mathrm{h}$ ) and increased the duration of the "on" period in the absence of severe dyskinesias ( $2.77 \mathrm{~h}$ compared with 0.80 h). PGI scores improved, which significantly reduced the equivalent dose of levodopa. In addition, there was a significant increase in the number of patients in the treatment group in whom a reduction in the duration of the "off" period was observed for $\geq 2$ hours. In most cases, the apomorphine infusion was well tolerated, and the observed side effects were only mild or moderate.

The most common adverse events were reported skin nodules at the injection site - in $44 \%$ of cases, nausea - in $22 \%$ and drowsiness - in $22 \%$ of cases [129].

It should be noted that levodopa was also used in clinical practice long before the results of the first randomised, double-blind, placebo-controlled study ELLDOPA were published in 2004 [128]. However, the lack of large-scale wound-based evidence has not prevented the widespread use of levodopa as the gold standard for the PD treatment worldwide. In contrast, although apomorphine had been used for almost 30 years, the lack of evidence for class I efficacy prevented its widespread use. There is reason to believe that the results of the TOLEDO study will inspire clinicians around the world to expand the use of apomorphine therapy and help to properly consider the use of the drug as an effective and competitive option for advanced treatment of PD, rather than as a last resort before recommending candidate for the use of levodopa/carbidopa - intestinal gel or DBS.

Under the leadership of S. Isaacson (2016), a special project that studied morning akinesia in patients with PD as a possible target for apomorphine injections, was performed in specialised clinics in the United States. The results of this open-label study also convincingly demonstrate that apomorphine injection significantly reduces the time to "turn on" on levodopa in severe stages in patients with PD, who experience morning akinesia as a result of delayed "turn on" or no effect of the morning dose of levodopa, and apomorphine injection is generally well tolerated by most patients.

On average, in these patients, there was a prolongation of time to the "'on" period on the morning dose of levodopa to one hour. The reduction in time to "turn on" (mean reduction by $37.14 \mathrm{~min}$ ) was clinically significant, as evidenced by a significant improvement in the quality of life and overall clinical impression scales that patients completed. Early morning akinesia, as a complication of levodopa therapy, was experienced by patients upon awakening as one of the first symptoms [89].

In a study conducted in Europe, it was shown that when progressive and deliberate questioning of patients with PD about the state of their morning physical activity, $\leq 60 \%$ of respondents reported early morning "off" periods of [90]. The results of the study showed that, despite such a high prevalence of the clinical phenomenon of morning dystonia, these phenomena often remain poorly detectable and therefore cannot be corrected by taking traditional oral antiparkinsonian drugs. And, despite their frequent use, patients suffered from morning akinesia for an average of about 4 years.

Thus, it was shown that after taking the first morning dose of levodopa for 7 days from the initial (initial) observation period $>40 \%$ of patients had at least one episode of "insufficient effect of a single dose", which was defined as no "on" period within 60 minutes after taking a dose of levodopa. This probably reflects a delay in the entry of levodopa from the stomach into the proximal intestine, where it should be absorbed (perhaps the remnants of protein food could still be in the intestine during awakening). It has been suggested that with slower gastric emptying, more levodopa may be metabolised by dopamine decarboxylase to dopamine in the gastric mucosa [88].

It was noted that in the treatment of apomorphine dosing ineffectiveness was much less common, and the average time to the "on" period when using subcutaneous apomorphine injection was about $24 \mathrm{~min}$, which suggests that the lack of "single dose of levodopa" may lie gastrointestinal dysfunction. Almost all subjects (95.5\%) showed a reduction in time before the start of the "on" period. 
The effect of apomorphine on motor activity was reliable and stable and was expressed in a significant improvement in Hoehn and Yahr and UPDRS-III scale, which was considered as an effect similar to the action of levodopa. For patients, a safer awakening and the ability to continue to perform routine morning activities and physical activity during the day were of clinical importance. All this suggests that patients assess morning akinesia as an obvious problem that significantly impairs their quality of life.

The most common reasons patients discontinued apomorphine were nausea, vomiting, and hypotension. The use of trimethobenzamide to relieve nausea and vomiting at the beginning and during the continuation of treatment with apomorphine injections showed that only $16 \%$ of patients who had previously received trimethobenzamide experienced nausea and/or had vomiting during the titration of the drug [91].

Thus, subcutaneous apomorphine injections provide a rapid and reliable on effect for patients with morning akinesia, presumably by eliminating the problem of delivery and absorption of the dose of levodopa-containing drug through the gastrointestinal tract. In addition to eliminating "off" episodes periods, apomorphine injections have clinical application to reduce early morning akinesia, providing a rapid and reliable on effect when using the drug after waking the patient.

Summary of the TOLEDO study: subcutaneous apomorphine infusion is relevant as a therapy for the treatment of Parkinson's disease with motor fluctuations that are not optimally controlled by oral antiparkinsonian drugs. The open-label phase of the study showed that apomorphine infusion was effective in reducing the "off" period (periods when levodopa-containing drugs did not work).

TOLEDO is a randomised placebo-controlled double-blind, multicentre study involving patients from 23 European clinical centres who were diagnosed with Parkinson's disease within 3 years or more of the disease and motor fluctuations were not adequately controlled by oral administration. those. All patients were randomised (1: 1) by computer randomization with a code stratified by groups, to take 3-8 $\mathrm{mg} / \mathrm{h}$ of apomorphine or placebo saline during waking hours (16 hours a day for 12 weeks). The infusion rate of the test drug and other oral drugs could be adjusted during the first 4 weeks based on individual efficacy and tolerability, after which patients were administered in an 8-week trial period.

This study was registered on ClinicalTrials.gov (NCT02006121) with results obtained from March 3, 2014. until March 1, 2016. 128 patients were selected according to the current criteria, and 107 were randomly assigned, of which 106 were included in the complete analytical sample ( $\mathrm{n}=53$ in both groups). apomorphine infusion (mean final dose $4.68 \mathrm{mg} / \mathrm{h}$ [SD 1.50]) significantly reduced the duration of the "off" period compared with placebo (-2.47 hours per day [SD 3.70] in the apomorphine group compared with $-0.58 \mathrm{~h}$ per day [2.80] in the placebo group, the difference is $1.89 \mathrm{~h}$ per day, $95 \% \mathrm{CI}$ from -3.16 to $0.62, \mathrm{p}=0.0025)[87]$.

In the original study, Marxreiter et al. (2018) analysed the efficacy of subcutaneous intermittent apomorphine infusions using mobile sensory analysis of walking in patients with Parkinson's disease with objective measurement of walking parameters in cross-sectional studies [93]. The aim of this study was to determine the extent to which the response to dopaminergic treatment of patients with PD can be quantified using sensory analysis of walking using special sensors. Thirteen patients with PD received apomorphine injections every 15 minutes to gradually increase the bioavailable dose of apomorphine. Motor activity (UPDRS III) was assessed $10 \mathrm{~min}$ after each apomorphine injection. Walking parameters were obtained after each assessment of UPDRS III parameters from the beginning of a $2 \times 10 \mathrm{~m}$ walk, providing a rate of $41.2 \pm 9.2$ steps per patient in response to each injection. A cross-sectional analysis showed that patients receiving apomorphine had improved stride speed and length, walking speed, maximum walking clearance, and toe angle. The magnitude of individual changes in velocity, length, and maximum foot clearance between injections correlated with improved motility in each patient. In addition, significant changes in stride length between drug injections correlated with improvement in UPDRS III. Thus, it is likely to be confirmed that sensory analysis of walking reflects objective changes in walking parameters, which confirm the level of clinical evaluation of the effectiveness of personalised dopaminergic treatment in patients with PD. The authors propose clinically significant instrumental indicators of walking parameters for studies of the effectiveness of single apomorphine infusions, which is especially important in clinical practice. 
This study also demonstrated that gait parameters, which are determined from clinical sensory analysis of gait, provide an objective assessment of gait quality that reflects improved motor activity in PD due to apomorphine.

It is shown that the use of instrumental analysis to measure individual changes in the parameter of walking speed, stride length and maximum foot clearance can be a personalised strategy for assessing routine clinical examinations of patients with PD.

Moreover, the proposed sensory systems of gait analysis, tested as an evaluation system of motor activity for possible transverse and longitudinal cohort studies. For example, inertial sensors (located on both wrists and ankles, as well as on the sternum and at the level of the fifth lumbar vertebra) can provide measurements of gait and balance in comparable groups, divided into subgroups by the off/on status. The results of sensory analysis of walking during a short consecutive walk (10-40 m) distinguished patients with PD from 42 patients in the control group and correlated with motor activity and stage of the disease in a cross-sectional analysis in 190 patients with PD [93]. In a longitudinal study, changes in gait parameters also differed between cohorts of patients with PD, correlating with the progression of movement disorders. Similarly, groups of patients in the off state of were compared with the group in the "on" period.

Thus, in a cross-sectional analysis of 12 patients receiving ART (Apomorphine Rapid Titration), it was shown that stride speed, walking speed, maximum foot clearance, turning time and stride length are a way to measure gait and serve as indicators of gait changes in response to apomorphine treatment. The findings suggest that instrumental analysis of walking serves as an objective measure of the therapeutic effect of the dopaminergic treatment paradigm proposed for clinical trials.

\section{Recommendations for the use of apomorphine in PD}

An international team of specialists with extensive clinical experience in the use of apomorphine in the treatment of patients with Parkinson's disease was invited by Britannia Pharmaceuticals Ltd., a manufacturer of injections and apomorphine infusions, to participate in an advisory board to share practical experience [130]. The purpose of the meetings was to develop a guide for neurologists, general practitioners and other health professionals on the optimal clinical use of apomorphine.

The first meeting took place in October 2012, the second - in May 2013, they were attended by 26 experts from 13 countries. All participants of the meeting joined the consensus group. The outcome of the two meetings of the Advisory Board led to a consensus on the recommendations for use in clinical practice.

The practice of subcutaneous apomorphine injections in PD, developed after analysing the data of questionnaires completed by members of the commission to implement the experience and recommendations for the use of apomorphine in clinical practice. In analysing the responses in the 26 completed questionnaires, consensus was considered reached when more than $80 \%$ of the experts agreed.

\section{Apomorphine in the treatment of parkinson's disease}

Apomorphine has low bioavailability when taken orally and the result of extensive metabolism of the first administration requires high doses to cause a clinical effect. Because nephrotoxicity has been reported in early pharmacodynamic studies of apomorphine, a special analysis of renal function was performed in animals undergoing chronic treatment with subcutaneous apomorphine injections, during which no signs of renal toxicity were detected with a similar route of administration [94].

Intermittent apomorphine injections have now been shown to be indicated in patients who experience recurrent "off" episodes due to delayed onset of clinically significant effects after oral administration of levodopa. Apomorphine is also recommended for use as a rescue medicine during "off" periods, which often occur after waking up. Intermittent apomorphine injection is recommended as a rescue treatment for patients who experience periods of "shortening the time of the single dose effect". Apomorphine injection provides a rapid onset of effect (usually within 4-12 minutes), and due to the rapid half-life, the average duration of antiparkinsonian action of the drug is about 45-60 $\mathrm{min}$ [95]. The 
most widely used forms of the drug are solutions of apomorphine hydrochloride in cartridges containing 10 or $20 \mathrm{mg} / \mathrm{ml}$, with a reusable syringe-pen.

Administration of apomorphine as an infusion is possible in cases where continuous dopaminergic stimulation is clinically necessary. The dose can be selected in order to achieve the optimal effect, the result of which is the continuous delivery of the drug to the "therapeutic window" in the period from 12 to 24 (usually 16) hours per day. In these cases, apomorphine is delivered through a subcutaneous catheter connected to a small portable pump fixed to the patient's waist or neck. Indications for prolonged infusion are usually unpredictable or prolonged "off" periods, motor fluctuations or dyskinesia.

Intermittent apomorphine injections have been shown to be a rapid and effective treatment for motor fluctuations in patients with PD [96-100].

It is emphasised that the decision to use apomorphine should be made taking into account the patient's symptoms and the degree of his disability as a result of motor complications, which have ceased to affect the optimal oral/transdermal therapy.

\section{When apomorphine therapy should be stopped or changed?}

There was a consensus that many patients were likely to discontinue apomorphine for no significant reason. The point of view of the experts was as follows: potentially reversible side effects usually cannot be a good reason to stop treatment. The significance of side effects varies from patient to patient, and the decision to prescribe or discontinue treatment should take into account the individual characteristics of each patient and the presence of discomfort caused by the injection, compared with oral therapy, which may affect the patient's compliance of apomorphine infusion and tolerability of side effects. Depending on the needs of a particular patient, he may not stop treatment with apomorphine in case of light or moderate subcutaneous nodules at the injection site, dyskinesias caused by additional oral drugs, non-haemolytic anaemia, non-threatening, mild hallucinations/hallucinations.

As a result, the analysis of questionnaires completed by a group of experts found that apomorphine treatment should be continued in the following situations:

- $\quad$ dyskinesias arising on the background of oral dopaminergic drugs;

- $\quad$ the alleged lack of efficacy in the occurrence of light skin nodules, especially those that can be controlled by treatment (see below);

- $\quad$ mild cognitive impairment;

- $\quad$ mild orthostatic hypotension.

\section{Management of side effects}

Effective management of side effects is the key to long-term apomorphine therapy. The experts discussed the frequency and severity of a number of adverse events and concluded that local reactions that occur during apomorphine infusion, such as nodule formation from minimal to moderate size at the infusion site, which are easily controlled by conventional methods. They include:

- $\quad$ change of infusion sites;

- $\quad$ use of Teflon ${ }^{\circledR}$ needles;

- $\quad$ regulation of subcutaneous infusion at the optimal angle $\left(45-90^{\circ}\right)$;

- $\quad$ skin hygiene and the use of emollients on the infusion side;

- $\quad$ choosing a lower concentration, such as $5 \mathrm{mg}$ per $1 \mathrm{ml}$, which has been used successfully;

- $\quad$ massage of the infusion site (rubber massage ball or vibrating massage device);

- application of ultrasound treatment;

- $\quad$ use of silicone gel bandages.

These methods are recommended based on clinical experience, but none have been confirmed by formal clinical studies, with the exception of ultrasound data, which have shown the effectiveness of its use in the treatment of nodules on the skin, making the treated side suitable for further injections of apomorphine [101]. 
The experts also noted that postural hypotension occurs on the background of apomorphine treatment infrequently, mainly in mild form, can be treated with non-pharmacological methods such as increased fluid and salt intake, elevated leg during sleep, slow torso changes, compression stockings and the addition of particular drugs such as mineralocorticoids or midodrine.

Neuropsychiatric adverse events, such as confusion, usually mild and infrequent, occur in approximately $10 \%$ of cases but may be severe. Impulse control disorders may occur, as with any other DA drug.

Panding, a manifestation of stereotyped (repetitive) behaviour, can be problematic as a manifestation of dopamine dysregulation syndrome.

Nausea is not a frequent or serious side effect of apomorphine infusion, although acute rescue apomorphine injections have been used in medicine in the past specifically to induce vomiting. Nausea can usually be controlled with pre-treatment with domperidone. Due to concerns about the possible prolongation of the QT interval on the electrocardiogram (ECG) in patients taking domperidone, the European Medicines Agency in March 2014 released updated recommendations for treatment with this drug. Domperidone is recommended for use in relieving symptoms of nausea and vomiting, and the dose should be reduced to no more than $10 \mathrm{mg}$ three times a day, and the drug should not normally be used for more than one week.

Haemolytic anaemia, as a potentially severe idiosyncratic adverse reaction, occurs rarely, in less than $1 \%$ of cases.

\section{Therapeutic indications of apomorphine}

When should apomorphine be used?

The first indication for the use of apomorphine should be a confirmed diagnosis of levodopasensitive Parkinson's disease [102-105]. Age is usually not a limiting factor, and mild cognitive impairment and postural symptoms are not contraindications. Indications for the use of apomorphine should include the presence in patients of refractory "off" periods, for example, when there is a delay in the onset of the effects of oral medication; long "off" periods after waking up; significant periods of "shortening the effect of a single dose of levodopa".

The drug can also improve non-motor symptoms, such as urinary incontinence, and serve as a diagnostic key in diagnosis.

The therapeutic response to maximum doses of levodopa does not necessarily indicate Parkinson's disease, but it is less consistent in patients with multisystem atrophy. Some patients with other parkinsonian syndromes do not respond or respond poorly to levodopa. in this regard, a study conducted by a group of scientists led by A. Lees, showed that apomorphine can be used as a diagnostic response test for levodopa with an accuracy of $90 \%$. The study showed that the reaction to apomorphine confirms the diagnosis of Parkinson's disease, while the lack of response indicates that this diagnosis is unlikely.

\section{Routes of administration of apomorphine}

Different routes of apomorphine administration have been investigated [106, 109-112, 118]. Oral administration was first tested by Cotzias et al., who gradually increased the dose to $1500 \mathrm{mg}$ per day [131]. 150 to $1440 \mathrm{mg}$ daily doses were generally well tolerated, but higher doses caused azotaemia. The bioavailability of apomorphine administered by this route is less than $4 \%$, so this route is considered impossible, because to achieve the desired effect requires very large doses, leading to significant side effects, such as nephrotoxicity, which is manifested in increased levels of creatinine and urea [107, 108]. The bioavailability of apomorphine taken under the tongue is also low $(10-22 \%)$, and the subcutaneous dose of $3 \mathrm{mg}$ and sublingual dose of $30 \mathrm{mg}$ have similar pharmacological profiles and clinical responses [113].

The spray for intranasal administration has a pharmacokinetic profile, similar to the profile of apomorphine, administered subcutaneously but requires prior premedication with domperidone [111, $113,117,118]$. 
In a study using apomorphine in $\mathrm{PD}$, no statistically significant differences were found between levodopa and apomorphine in the effect of drugs on clinical symptoms in PD, measured using the UPDRS scale [108].

The first dose of apomorphine is recommended to be administered in a hospital to monitor the clinical response and determine the individual therapeutic dose during drug titration.

Oral domperidone (10-20 mg 3 times daily) should be started one to three days before apomorphine therapy.

Currently, Penject (intermittent injection) and portable pump (continuous infusion) are approved in most European countries, where their use is of great importance in the treatment of Parkinson's disease with confirmation of good results [114-116]. Hughes et al. published a study of 71 patients who received intermittent injections (10 injections per day) or continuous apomorphine infusions when more than 10 injections were required [133].

A 50\% reduction in the "off" period was observed in 49 patients who received intermittent injections. One year after treatment, $80 \%$ of patients reported that apomorphine treatment was still effective.

Intermittent apomorphine infusion (Penject) was performed using an insulin syringe mounted in a pen-injector with predetermined doses for ease of administration [132]. The injection site may be the anterior abdominal wall, arms and thighs.

Basic rules for starting the primary titration of apomorphine dose:

1. Premedication with domperidone (10-20 mg three times/day, started one to three days before apomorphine therapy).

2. The infusion may be given if the patient has not taken dopamine for 12 to 24 hours. Levodopa should be discontinued the night before the test.

3. Before the test, it is necessary to measure blood pressure in a supine and sitting position.

4. Dose titration should begin with 1-1.5 $\mathrm{mg}$ of apomorphine subcutaneously.

Record UPDRS III score (before and after apomorphine administration - "on", "off") and any side effects (nausea, orthostatic hypotension, drowsiness and dyskinesia).

5. Repeat apomorphine at intervals of 1-1.5 hours, increasing the dose by $1 \mathrm{mg}$ to a good or acceptable clinical effect.

You can use no more than 7-8 $\mathrm{mg}$ of apomorphine per hour, $10 \mathrm{mg}$ per injection. The apomorphine solution is supplied in a concentration of $1 \mathrm{mg} / 0.1 \mathrm{ml}$ in $3 \mathrm{ml}(30 \mathrm{mg})$ in glass cartridges with a manual reusable multi-dose injector-handle, releasing doses from $0.02 \mathrm{ml}$ to $1 \mathrm{ml}(10 \mathrm{mg})$. To minimise errors in efficacy estimates, the dose of apomorphine should be administered in millilitres (not milligrams) using an injector pen. The optimal therapeutic dose of the drug is $0.3 \mathrm{ml}$ and $0.5 \mathrm{ml}$ or $3 \mathrm{mg}$ and $5 \mathrm{mg}$. Once the optimal dose has been determined, it rarely needs to be adjusted. The half-life of apomorphine is 45 minutes and the minimum recommended time between injections is 60 minutes.

When administered subcutaneously, the drug is rapidly absorbed, reaching the maximum level in the serum occurs in 20 minutes, and the clinical effect is observed in 5-15 minutes after administration. Apomorphine is usually prescribed for a short period of time. The average daily dose is $3-30 \mathrm{mg} /$ day and provides the selected dose, which is necessary to alleviate the "off" period. intermittent apomorphine infusion is a good rescue therapy in cases of motor fluctuations, such as "shortening of a single dose of levodopa" and fluctuations in periods of "on-off", due to the rapid onset of action of the drug. If necessary, apomorphine should be used as a rescue medicine during "off" periods without changing the regimen of levodopa. The drug can completely change the predicted and unpredictable "off" periods, it prolongs the "on" period and helps with morning or night akinesia, painful dystonia and is an appropriate choice when absorption of oral levodopa is difficult due to delayed gastric emptying.

Apomorphine can also improve psychiatric symptoms such as depression and panic attacks. Some surgical centres use apomorphine, which is administered with a syringe pen, as a rescue medicine in patients before surgery when oral medications cannot be taken. 
1) haemolytic anaemia;

2) ECG changes (QT prolongation, atrial fibrillation, tachycardia, bradyarrhythmia, premature ventricular contractions);

3) use of anticoagulants;

4) diabetes and other diseases that prevent the healing of surgical wounds;

5) cellulite and other local infections;

6) hypersensitivity to apomorphine or components of the solution, such as sodium metabisulfite;

7) severe mental symptoms.

\section{Undesirable effects}

The most common long-term undesirable effect of apomorphine injections is nodules at the injection site in $70 \%$ of people [134].

Some patients may experience itching, bruising, or pain. These local side effects are related to the concentration of the drug, the time of infusion or the depth of injection.

In some patients (10-20\%), the reactions may be more pronounced - in the form of necrotic nodular ulcers. This problem can be solved by changing the injection site daily, providing asepsis, using silicone gel patches, or, in some cases, may require the use of ultrasound treatment [103].

Periodically, haematological tests are recommended to avoid the risk of haemolytic anaemia [107].

ECG changes in the form of QT prolongation may occur at doses of $6 \mathrm{mg}$ or more. Prophylactic treatment with dopamine antagonists (eg metoclopramide) and serotonin receptor antagonists (eg granisetron and ondansetron) should be avoided because the drugs may interact with apomorphine by penetrating the blood-brain barrier.

Doses above $6 \mathrm{mg}$ have no additional benefits and are therefore not recommended [107].

\section{Traditional oral therapy compared to apomorphine}

It has been shown that the quality of the clinical response to oral levodopa is similar to the quality of the response to apomorphine [103]. However, apomorphine, eliciting a shorter and faster motor response, confirms that the integrity of postsynaptic receptors is a key factor in determining the dopamine response in the treatment of Parkinson's disease. In other words, clinical reactions to drugs may be similar; they all have different mechanisms of action [103, 105]. Yes, apomorphine has certain advantages compared to levodopa. First of all, this is a method of prescribing the drug in the form of monotherapy, which is able to increase the duration of the "on" period of levodopa and thus maintain continuous dopamine stimulation. It is equally important that the patient has a reduced need for levodopa, which, in turn, leads to a decrease in dyskinesias and motor fluctuations [102, 106].

Moreover, when administered parenterally, apomorphine improves adherence to treatment in patients who do not tolerate oral drugs or in whom their absorption is not stable. On the other hand, to work with the pump requires the help of relatives or guardians. In addition, apomorphine rapidly crosses the blood-brain barrier independently of the active transport system, without competing with proteins and blood circulation [104].

\section{Comparison of apomorphine with oral form of levodopa}

As discussed above, apomorphine is the only commercially available dopamine agonist that, like levodopa, stimulates D1- and D2-like receptors. The profile of these receptors is the reason that apomorphine, but not other dopamine agonists, can cause a reaction similar to that of levodopa. In an earlier study, Kempster et al. the magnitude and nature of motor responses to single doses of subcutaneous apomorphine and oral levodopa in 14 patients with PD were compared.

It has been shown that, although apomorphine worked much shorter and faster than levodopa, the quality of the clinical response to both drugs was almost the same [83]. In many clinical studies described above, the optimal dose of apomorphine was determined to provide at least $90 \%$ of the 
apparent response on the UPDRS scale compared to levodopa. In study AP0202 performed in the United States, a "levodopa-like" effect was further confirmed by a similar increase in the speed of the tapping test in the finger test (the ratio of 236 clicks during the "off" period to 374 clicks during the "on" period with apomorphine and 356 clicks in the "on" state when using levodopa). There was also a reduction in step time during the Webster second test (a decrease from $431 \mathrm{~s}$ in the "off" state to $128 \mathrm{~s}$ in the "on" state with apomorphine and $124 \mathrm{~s}$ in the "on" state with levodopa] [39].

It is also important to note that apomorphine acts faster than levodopa, even when levodopa is administered in a dispersed form. It is established that among all available antiparkinsonian drugs apomorphine causes the most rapid relief of symptoms of the "off" period in patients with PD with motor fluctuations. Thus, in one of the few direct studies by Merello et al. analysed the delay and duration of apomorphine injections compared to the dispersed form of levodopa/benserazide. In this small but randomised blinded study, 12 patients with highly fluctuating symptoms received a single dose of apomorphine or a dispersed form of levodopa for 2 consecutive days. The study showed that the amplitude of responses was the same for both drugs (using a modified Webster test), but apomorphine more quickly eliminated the "off" periods (latency of the effect of $8.08 \mathrm{~min}$ for apomorphine versus 26.8 min for dispersed levodopa).

The phenomenon of motor fluctuations as a complication of long-term levodopa therapy in patients with PD is a real challenge, which encourages the development of new means of correction of this severe clinical symptom. In the past, the use of prolonged forms of agonists, such as per-halide or bromocriptine in combination with levodopa, provided a significant opportunity to affect the duration of the "off" period, but, unfortunately, improved dopamine stimulation in these cases was combined with side effects such as dyskinesia or hallucinations, which led to a significant restriction on the use of these drugs.

A promising approach to the treatment of patients with motor fluctuations in the form of on/"off" periods should be recognised as an early start of treatment of this phenomenon. In this double-blind study, apomorphine proved to be the fastest drug compared to the fast-dissolving drug levodopa. Even if apomorphine injections were problematic for some patients and required the assistance of a specially trained physician, the rapid onset of apomorphine, according to this study, made it the drug of choice to eliminate severe "off" periods [134].

Animal data show that apomorphine has an antiparkinsonian effect by directly interacting with postsynaptic dopamine receptors of the striatum. The administration of apomorphine actually inhibits the pulsating (intermittent) stimulation of receptors and, presumably, the synaptic release of dopamine by neurons of the nigrostriatal body by stimulating presynaptic dopamine receptors. The equivalence of the clinical response to apomorphine and levodopa contradicts the notion of a fundamentally different mechanism of action of levodopa, which is usually associated with the physiological recovery of synaptic dopaminergic neurotransmission by preservation of nigrostriatal terminals. If this was true, it could be assumed that differences in the degree of response to the action of both agents will be detected, especially in patients in advanced stages of the disease, which will clinically reflect a more pronounced loss of nigral dopaminergic neurons. The results obtained can be compared with hypothesis of E. Melamed on the non-physiological effects of levodopa [119]. The author suggested that exogenous levodopa may undergo biotransformation to dopamine at various loci of the striatum, penetrating the extracellular space and interacting with postsynaptic dopamine receptors to bypass the presynaptic activity of degenerated nigrostriatal terminals. The consequence of this concept may be that levodopa and the dopamine receptor agonist apomorphine have similar pharmacodynamics in the striatum, and clinically this is reflected in an equivalent improvement in the patient's motor image. While the level of nigral cell loss and, consequently, endogenous dopamine deficiency in the striatum is most likely to determine the severity of the "off" period, the "on" period, as the clinical severity of motor impairment compensation, depends on the sensitivity of postsynaptic dopamine receptors. striped body, which is the basis for the preservation of the main non-dopaminergic components of the extrapyramidal motor system. 


\section{Apomorphine and non-motor symptoms}

Although the evaluation of the effectiveness of apomorphine in the treatment of motor symptoms of PD has been the focus of most studies, the question of the possibility of the drug's effect on non-motor aspects of the disease naturally continues to arise. It is known that non-motor symptoms have $>90 \%$ of patients with PD, which affects many factors that determine their quality of life. The range of non-motor symptoms is wide and includes psycho-neurological symptoms, sleep disorders, pain, cognitive impairment, weakness, depression, etc. Patients with PD have an average of 8.3 non-motor symptoms during the course of the disease [120]. Some authors, focusing on the effects of apomorphine on neuropsychiatric symptoms, argue that apomorphine is well tolerated in patients with paranoid ideas and visual hallucinations [121, 122]. It has been suggested that the hypothetical antipsychotic effect of apomorphine may be related to its structural piperidine moiety, which is also part of several antipsychotic molecules. It has also been shown that, compared to other dopamine agonists, the positive effect of apomorphine treatment is probably associated with a lower risk of impulse control disorders $[123,124]$. On the other hand, activation of D3 receptors by oral dopamine agonists has been associated with the possibility of induction of impulsive-compulsive disorders in PD [125].

A recent experimental study showed that apomorphine injections reduced the expression of intraneural $\beta$-amyloid protein and improved short-term memory in a mouse model of Alzheimer's disease [126]. Based on these results, a recent retrospective clinical neuroimaging study examined nondementia patients with PD who were constantly taking apomorphine compared with controls. Positron emission tomography revealed a decrease in $\beta$-amyloid protein levels in subjects receiving apomorphine, suggesting that the drug may be used to reduce cognitive impairment in PD [127].

Thus, data on the effectiveness of apomorphine in non-motor symptoms indicate a possible benefit in sleep disorders, psychoneurological symptoms, urinary tract dysfunction, possible effects on mood and gastrointestinal symptoms due to reduced off time in patients with severe PD.

\section{Conclusions}

It should be assumed that PD is a clinical reflection of neurotransmitter imbalance in the central nervous system, and apomorphine, which has many pharmacological effects that underlie the multimodal action on several of these systems, will have a positive assessment, in addition to other drugs acting on certain subtypes of dopamine receptors. In this aspect, the pharmacodynamic effects of apomorphine are significantly different, and apomorphine should not be considered only as a "simple" dopamine agonist. Apomorphine is the only drug currently available that has the same antiparkinsonian effect as levodopa. Apomorphine has the fastest onset of action compared to all currently used antiparkinsonian drugs. The method of application of apomorphine is important to justify two very different therapeutic approaches to the use of the drug in PD. Introduced as a subcutaneous injection, the drug reliably and quickly relieves the patient of "off" periods and provides patients with severe motor fluctuations better control and independence of movement, adequate daily activity and a decent quality of life.

Author Contributions: All authors participated equally in writing this article.

Conflicts of Interest: The authors declare no conflict of interest.

\section{Information about Authors:}

Iryna M. Karaban - DSc (Medicine), Prof., Head of the Department of Clinical Physiology and Pathology of Extrapyramid Nervous System; https://orcid.org/0000-0003-0849-8950

Nina V. Karasevych - PhD (Medicine), Leading Researcher of the Department of Clinical Physiology and Pathology of Extrapyramid Nervous System; https://orcid.org/0000-0001-9373-1432

Tetyana V. Hasiuk - Researcher of the Department of Clinical Physiology and Pathology of Extrapyramid Nervous System; 


\section{References}

1. Colosimo, C.; De Michele, M. Motor fluctuations in Parkinson's disease: pathophysiology and treatment. Eur J Neurol 1999, 6, 1-21. https://doi.org/10.1046/j.1468-1331.1999.610001.x

2. Olanow, C. W.; Gracies, J. M.; Goetz, C. G.; Stoessl, A. J.; Freeman, Th. et al. Clinical pattern and risk factors for dyskinesias following fetal nigral transplantation in Parkinson's disease: a double blind video-based analysis. Mov Disord 2009, 24,3, 336-43 4. https://doi.org/10.1002/mds.22208

3. Witjas, T.; Kaphan, E.; Azulay, J. P.; Blin, O.; Ceccaldi, M. et al. Nonmotor fluctuations in Parkinson's disease: frequent and disabling. Neurology 2002, 59, 3, 408-13. https://doi.org/10.1212/wn1.59.3.408

4. Obeso, J. A.; Rodriguez-Oroz, M.; Marin, C.; Alonso, F.; Zamarbide, I.et al. The origin of motor fluctuations in Parkinson's disease: importance of dopaminergic innervation and basal ganglia circuits. Neurology 2004, 62, 1, 1, S17-30. https://doi.org/10.1212/wnl.62.1_suppl_1.s17

5. Jenner P. From the MPTP-treated primate to the treatment of motor complications in Parkinson's disease. Parkinsonism Relat Disord 2009, 15, 4, S18-23. https://doi.org/10.1016/s1353-8020(09)708296

6. Brotchie, J. M. Nondopaminergic mechanisms in levodopa-induced dyskinesia. Mov Disord 2005, 20, 8, 919-31. https://doi.org/10.1002/mds.20612

7. Kurlan, R.; Rothfield, K. P.; Woodward, W. R.; Nutt, J. G.; Miller, C. et al. Erratic gastric emptying of levodopa may cause "random" fluctuations of parkinsonian mobility. Neurology 1988, 38, 3, 419-21. https://doi.org/10.1212/wnl.38.3.419

8. Nyholm, D.; Askmark, H.; Gomes-Trolin, C.; Knutson, T.; Lennernas, H. et al. Optimizing levodopa pharmacokinetics: intestinal infusion versus oral sustained-release tablets. Clin Neuropharmacol 2003, 26, 3, 156-63. https://doi.org/10.1097/00002826-200305000-00010

9. Jenner, P. Dopamine agonists in Parkinson's disease-focus on non-motor symptoms. Eur J Neurol 2008, 15, 2, 1. https://doi.org/10.1111/j.1468-1331.2008.02211.x

10. Stocchi, F.; Nordera, G.; Marsden, C. D. Strategies for treating patients with advanced Parkinson's disease with disastrous fluctuations and dyskinesias. Clin Neuropharmacol 1997, 20, 2 , 95-115. https://doi.org/10.1097/00002826-199704000-00001

11. Stocchi, F.; Ruggieri, S.; Vacca, L.; Olanow, C. W. Prospective randomized trial of lisuride infusion versus oral levodopa in patients with Parkinson's disease. Brain 2002, 125, 9, 2058-2066. https://doi.org/10.1093/brain/awf214

12. Lees, A. J. Dopamine agonists in Parkinson's disease: a look at apomorphine. Fundam. Clin. Pharmacol. 1993,7, 121e128. https://doi.org/10.1111/j.1472-8206.1993.tb00226.x

13. Ernst, A. M. Relation between the action of dopamine and apomorphine and their O-methylated derivatives upon the CNS. Psychopharmacologia 1965, 7, 391-399.

https://doi.org/10.1007/BF00402361

14. Colosimo, C.; Merello, M.; Albanese, A. Clinical usefulness of apomorphine in movement disorders. Clin. Neuropharmacol. 1994, 17, 243-259. https://doi.org/10.1097/00002826-1994060000000

15. Corsini, G. U.; Del Zompo, M.; Gessa, G. L.; Mangoni, A. Therapeutic efficacy of apomorphine combined with an extracerebral inhibitor of dopamine receptors in Parkinson's disease. Lancet 1979, 1, 954e956. https://doi.org/10.1016/s0140-6736(79)91725-2

16. Stibe, C.; Lees, A.; Stern, G. Subcutaneous infusion of apomorphine and lisuride in the treatment of parkinsonian on-off fluctuations. Lancet 1987, 1, 871. https://doi.org/10.1016/s01406736(87)91660-6

17. Stibe, C. M.; Lees, A. J.; Kempster, P. A.; Stern, G. M. Subcutaneous apomorphine in parkinsonian on-off oscillations. Lancet 1998, 1, 403-406. https://doi.org/10.1016/s0140-6736(88)91193-2

18. Hughes, A. J.; Bishop, S.; Stern, G. M.; Lees, A. J. The motor response to repeated apomorphine administration in Parkinson's disease. Clin Neuropharmacol 1991, 14, 209-213. https://doi.org/10.1097/00002826-199106000-00003

19. Hughes A. J.; Lees, A. J.; Stern, G. M. The motor response to sequential apomorphine in parkinsonian fluctuations. J Neurol Neurosurg Psychiatry 1991, 54, 358-360.

https://doi.org/10.1136/jnnp.54.4.358 
20. Poewe, W.; Wenning, G. K Apomorphine: an underutilized therapy for Parkinson's disease. Mov Disord 2000, 15, 789-794.

21. Poewe, W.; Lees, A.; Chaudhuri, K.R.; Isaacson, S. New perspectives in non-oral drug delivery in Parkinson's disease. Eur. Neurol. Rev. 2014, 9, 31-36. https://doi.org/10.17925/ENR.2014.09.01.i

22. Martinez-Martin, P.; Reddy, P.; Antonini, A.; Henriksen, T.; Katzenschlager, R. et al. Chronic subcutaneous infusion therapy with apomorphine in advanced Parkinson's disease compared to conventional therapy: a real life study of non motor effect. J Park Dis 2011, 1, 197-203. https://doi.org/10.3233/jpd-2011-11037

23. Frankel, J. P.; Lees, A. J.; Kempster, P. A.; Stern, G. M. Subcutaneous apomorphine in the treatment of Parkinson's disease. J Neurol Neurosurg Psychiatry 1990, 53, 2, 96-101. https://doi.org/10.1136/jnnp.53.2.96

24. Hilker, R.; Antonini, A.; Odin, P. What is the best treatment for fluctuating Parkinson's disease: continuous drug delivery or deep brain stimulation of the subthalamic nucleus? J Neural Transm 2011, 118, 6, 907-914. https://doi.org/10.1007/s00702-010-0555-8

25. Hardie, R. J.; Lees, A. J.; Stern, G. M. On-off fluctuations in Parkinson's disease: a clinical and neuropharmacological study. Brain 1984, 107, 2, 487-506. https://doi.org/10.1093/brain/107.2.487

26. Stibe, C. M.; Lees, A. J.; Kempster, P. A.; Stern, G. M. Subcutaneous apomorphine in parkinsonian on-off oscillations. Lancet 1988, 1, 8582, 403-406. https://doi.org/10.1016/S0140-6736(88)91193-2

27. Hilker, R.; Antonini, A.; Odin, P. What is the best treatment for fluctuating Parkinson's disease: continuous drug delivery or deep brain stimulation of the subthalamic nucleus? J Neural Transm 2011, 118, 6, 907-914. https://doi.org/10.1007/s00702-010-0555-8

28. Wenzel, K.; Homann, C. N.; Fabbrini, G.; Colosimo,C. The role of subcutaneous infusion of apomorphine in Parkinson's disease. Expert Rev Neurother 2014, 14, 7, 833-843. https://doi.org/10.1586/14737175.2014.928202

29. Cotzias, G. C.; Papavasiliou, P. S.; Fehling, C.; Kaufman, B.; Mena, I. Similarities between neurologic effects of L-dopa and of apomorphine. N Engl J Med 1970, 282, 1, 31-33. https://doi.org/10.1056/NEJM197001012820107

30. Lees, A. J. Dopamine agonists in Parkinson's disease: a look at apomorphine. Fundam Clin Pharmacol 1993, 7, 3-4, 121-128. https://doi.org/10.1111/j.1472-8206.1993.tb00226.x

31. Schwab, R. S.; Amador, L. V.; Lettvin, J. Y. Apomorphine in Parkinson's disease. Trans Am Neurol Assoc 1951, 56, 251-3.

32. Henriksen, T. Clinical insights into use of apomorphine in Parkinson's disease: tools for clinicians. Neurodegener Dis Manag 2014, 4, 3, 271-282. https://doi.org/10.2217/nmt.14.17

33. Kleedorfer, B.; Turjanski, N.; Ryan, R.; Lees, A. J.; Milroy, C.; Stern, G. M. Intranasal apomorphine in Parkinson's disease. Neurology 1991, 41, 5, 761-762. https://doi.org/10.1212/WNL.41.5.761-a

34. Hughes, A. J.; Webster, R; Bovingdon, M.; Lees, A. J. Stern, G. M. Sublingual apomorphine in the treatment of Parkinson's disease complicated by motor fluctuations. Clin Neuropharmacol 1991, 14, 6, 556-561. https://doi.org/10.1097/00002826-199112000-00008

35. Manson, A. J.; Hanagasi, H.; Turner, K.; Patsalos, P. N.; Carey, P. et al. Intravenous apomorphine therapy in Parkinson's disease: clinical and pharmacokinetic observations. Brain 2001, 124, 2, 331340. https://doi.org/10.1093/brain/124.2.331

36. Menon, R.; Stacy, M. Apomorphine in the treatment of Parkinson's disease. Expert Opin Pharmacother 2007, 8, 12, 1941-1950. https://doi.org/10.1517/14656566.8.12.1941

37. Millan, M.J.; Maiofiss, L.; Cussac, D.; Audinot, V.; Boutin, J. A.; Newman-Tancredi, A. Differential actions of antiparkinson agents at multiple classes of monoaminergic receptor. I. A multivariate analysis of the binding profiles of 14 drugs at 21 native and cloned human receptor subtypes. $J$ Pharmacol Exp Ther 2002, 303, 791-804. https://doi.org/10.1124/jpet.102.039867

38. Dankova, J.; Bedard, P.; Langelier, P.; Poirier, L. J. Dopaminergic agents and circling behaviour. Gen Pharmacol 1978, 9, 295-302. https://doi.org/10.1016/0306-3623(78)90064-2

39. Newman-Tancredi, A.; Cussac, D.; Audinot, V.; Nicolas, J. P.; De Ceuninck, F. et al. Differential actions of antiparkinson agents at multiple classes of monoaminergic receptor. II. Agonist and antagonist properties at subtypes of dopamine $\mathrm{D}(2)$-like receptor and alpha(1)/alpha(2)adrenoceptor. J Pharmacol Exp Ther 2002, 303, 805-814. https://doi.org/10.1124/jpet.102.039875 
40. Antonini, A.; Tolosa, E.; Mizuno, Y.; Yamamoto, M.; Poewe, W. H. A reassessment of risks and benefits of dopamine agonists in Parkinson's disease. Lancet Neurol 2009, 8, 929-937. https://doi.org/10.1016/s1474-4422(09)70225-x

41. Feyder, M.; Bonito-Oliva, A.; Fisone, G. L-DOPA-Induced Dyskinesia and Abnormal Signaling n striatal medium spiny neurons: focus on dopamine D1 receptor-mediated transmission. Front Behav Neurosci 2011, 5, 71. https://doi.org/10.3389/fnbeh.2011.00071

42. Guigoni, C.; Bezard, E. Involvement of canonical and non-canonical D1 dopamine receptor signalling pathways in L-dopa-induced dyskinesia. Park Relat Disord 2009, 3, 15, S64-S67. https://doi.org/10.1016/s1353-8020(09)70783-7

43. Mailman, R.; Huang, X.; Nichols, D. E. Parkinson's disease and D1 dopamine receptors. Curr Opin Investig 2001, 2, 1582-1591.

44. Blanchet, P. J.; Fang, J.; Gillespie, M.; Sabounjian, L.; Locke, K. W. et al. Effects of the full dopamine D1 receptor agonist dihydrexidine in Parkinson's disease. Clin Neuropharmacol 1998, 21, 339-343.

45. Yoshimura, N.; Mizuta,E.; Kuno, S.; Sasa, M.; Yoshida, O. The dopamine D1 receptor agonist SKF 38393 suppresses detrusor hyperreflexia in the monkey with parkinsonism induced by 1-methyl4-phenyl-1,2,3,6- tetrahydropyridine (MPTP). Neuropharmacology 1993, 32, 315-321. https://doi.org/10.1016/0028-3908(93)90151-r

46. Andersson, K. E.; Treatment of overactive bladder: other drug mechanisms. Urology 2000, 55, 5157. https://doi.org/10.1016/s0090-4295(99)00495-1

47. Seeman, P. Parkinson's disease treatment may cause impulse-control disorder via dopamine D3 receptors. Synapse 2015, 69, 183-189. https://doi.org/10.1002/syn.21805

48. Horowski, R.; Jahnichen, S.; Pertz, H. H. Fibrotic valvular heart disease is not related to chemical class but to biological function: 5-HT2B receptor activation plays crucial role. Mov Disord 2004, 19, 1523-1524.

49. Antonini, A.; Poewe, W. Fibrotic heart-valve reactions to dopamine-agonist treatment in Parkinson's disease. Lancet Neurol 2007, 6, 826-829. https://doi.org/10.1016/s1474-4422(07)70218-1

50. Andersohn, F.; Garbe, E. Cardiac and noncardiac fibrotic reactions caused by ergot-and nonergotderived dopamine agonists. Mov Disord 2009, 24, 129-133. https://doi.org/10.1002/mds.22385

51. Geerligs, L.; Meppelink, A. M.; Brouwer, W. H.; van Laar, T. The effects of apomorphine on visual perception in patients with Parkinson disease and visual hallucinations: a pilot study. Clin Neuropharmacol 2009, 32, 266-268. https://doi.org/10.1097/wnf.0b013e3181a6a92b

52. Borgemeester, R. W.; Lees, A. J.; van Laar, T. Parkinson's disease, visual hallucinations and apomorphine: a review of the available evidence. Park Relat Disord 2016, 27, 35-40. https://doi.org/10.1016/j.parkreldis.2016.04.023

53. Sharma, J. C.; Macnamara, L.; Hasoon, M.; Vassallo, M. Diagnostic and therapeutic value of apomorphine in Parkinsonian patients. Int J Clin Pract 2004, 58, 1028-1032. https://doi.org/10.1111/j.1368-5031.2004.00357.x

54. Hughes, A. J.; Lees, A. J.; Stern, G. M. The motor response to sequential apomorphine in parkinsonian fluctuations. J Neurol Neurosurg Psychiatry 1991, 54, 4, 358-360. https://doi.org/10.1136/jnnp.54.4.358

55. O'Sullivan, J. D.; Lees, A. J. Use of apomorphine in Parkinson's disease. Hosp Med 1999, 60, 11, 816-820. https://doi.org/10.12968/hosp.1999.60.11.1236

56. Frankel, J. P.; Lees, A. J.; Kempster, P. A.; Stern, G. M. Subcutaneous apomorphine in the treatment of Parkinson's disease. J Neurol Neurosurg Psychiatry 1990, 53, 2, 96-101. https://doi.org/10.1136/jnnp.53.2.96

57. Hagell, P.; Odin, P. Apomorphine in Parkinson's disease. 3rd ed. UNI-MED: Bremen, 2014; p.95

58. Ramirez-Zamora, A.; Molho, E. Treatment of motor fluctuations in Parkinson's disease: recent developments and future directions. Expert Rev Neurother 2014, 14, 1, 93-103. https://doi.org/10.1586/14737175.2014.868306

59. Obering, C. D.; Chen, J. J. Swope DM. Update on apomorphine for the rapid treatment of hypomobility ("off") episodes in Parkinson's disease. Pharmacotherapy 2006, 26, 6, 840-852. https://doi.org/10.1592/phco.26.6.840 
60. Lees, A. J. Dopamine agonists in Parkinson's disease: a look at apomorphine. Fundam Clin Pharmacol 1993, 7, 3-4, 121-128. https://doi.org/10.1111/j.1472-8206.1993.tb00226.x

61. Henriksen, T. Clinical insights into use of apomorphine in Parkinson's disease: tools for clinicians. Neurodegener Dis Manag 2014, 4, 3, 271-282. https://doi.org/10.2217/nmt.14.17

62. Martinez-Martin, P.; Reddy, P.; Antonini, A.; Henriksen, T.; Katzenschlager, R. et al. Chronic subcutaneous infusion therapy with apomorphine in advanced Parkinson's disease compared to conventional therapy: a real life study of non motor effect. J Parkinsons Dis 2011, 1, 2, 197-203. https://doi.org/10.3233/jpd-2011-11037

63. Menon, R.; Stacy, M. Apomorphine in the treatment of Parkinson's disease. Expert Opin Pharmacother 2007, 8, 12, 1941-1950. https://doi.org/10.1517/14656566.8.12.1941Pessoa RR et al. Apomorphine: a review 847

64. Pfeiffer, R. F.; Gutmann, L.; Hull, K. L. Jr.; Bottini, P. B.; Sherry, J. H. Continued efficacy and safety of subcutaneous apomorphine in patients with advanced Parkinson's disease. Parkinsonism Relat Disord 2007, 13, 2, 93100.https://doi.org/10.1016/j.parkreldis.2006.06.012

65. Kempster, P. A.; Frankel, J. P.; Stern, G. M.; Lees, A. J. Comparison of motor response to apomorphine and levodopa in Parkinson's disease. J Neurol Neurosurg Psychiatry 1990, 53, 11, 1004-1007. https://doi.org/10.1136/jnnp.53.11.1004

66. Colosimo, C.; Merello, M.; Hughes, A. J.; Sieradzan, K.; Lees, A. J. Motor response to acute dopaminergic challenge with apomorphine and levodopa in Parkinson's disease: implications for the pathogenesis of the on-off phenomenon. J Neurol Neurosurg Psychiatry 1996, 60, 6, 634-637. https://doi.org/10.1136/jnnp.60.6.634

67. Stibe, C.M.; Lees, A.J.; Kempster, P.A.; Stern, G.M. Subcutaneous apomorphine in parkinsonian on-off oscillations. Lancet 1998, 1, 403-406. https://doi.org/10.1016/s0140-6736(88)91193-2

68. Poewe, W.; Kleedorfer, B.; Wagner, M.; Benke, T.; Gasser, T.; Oertel, W. Sideeffects of subcutaneous apomorphine in Parkinson's disease. Lancet 1989, 1, 1084, 1050. https://doi.org/10.1016/s0140-6736(89)92487-2

69. Odin, P. Intermittent subcutaneous apomorphine injection. Odin, P.; P. Hagell, P.; Shing M. Eds., Apomorphine in Parkinson's Disease, 3 ed., UNIMED Verlag AG: Bremen, 2005; pp. 35-36.

70. Isaacson, S.; Lew, M.; Ondo, W.; Hubble, J.; Clinch,T.; Pagan, F. Apomorphine subcutaneous injection for the management of morning akinesia in Parkinson's disease. Movmnt Disords Clncl Pract 2016. http://dx.doi.org/10.1002/ mdc3.12350.

71. Colosimo, C.; De Michele, M. Motor fluctuations in Parkinson's disease: pathophysiology and treatment. Eur J Neurol 1999, 6, 1-21. https://doi.org/10.1046/j.1468-1331.1999.610001.x

72. Golbe, L. I. Young-onset Parkinson's disease: a clinical review. Neurology 1991, 41, 2, 1, 168-173. https://doi.org/10.1212/wnl.41.2_part_1.168

73. Olanow, C. W.; Gracies, J. M.; Goetz, C. G. et al. Clinical pattern and risk factors for dyskinesias following fetal nigral transplantation in Parkinson's disease: a double blind video-based analysis. Mov Disord 2009, 24, 3, 336-343. https://doi.org/10.1002/mds.22208

74. Cotzias, G. C.; Papavasiliou, P. S.; Fehling, C.; Kaufman, B.; Mena, I. Similarities between neurologic effects of L-dipa and of apomorphine. N Engl J Med 1970, 282, 1, 31-33. https://doi.org/10.1056/nejm197001012820107

75. Stibe, C. M.; Lees, A. J.; Kempster, P. A.; Stern, G. M. Subcutaneous apomorphine in parkinsonian on-off oscillations. Lancet 1988, 1, 8582, 403-406. https://doi.org/10.1016/s0140-6736(88)91193-2

76. Poewe, W.; Kleedorfer, B.; Wagner, M. et al. Side-effects of subcutaneous apomorphine in Parkinson's disease. Lancet, 1989, 1, 8646, 1084-1085.

77. Kempster, P. A.; Iansek, R.; Larmour, I. Intermittent subcutaneous apomorphine injection treatment for parkinsonian motor oscillations. Aust N Z J Med 1991, 21, 3, 314-318. https://doi.org/10.1111/j.1445-5994.1991.tb04696.x

78. Hughes, A. J.; Bishop, S.; Kleedorfer, B.; Turjanski, N.; Fernandez, W. et al. Subcutaneous apomorphine in Parkinson's disease: response to chronic administration for up to five years. Mov Disord 1993, 8, 2, 165-170. https://doi.org/10.1002/mds.870080208

79. Merello, M.; Leiguarda, R. [Treatment of motor fluctuations in Parkinson's disease with subcutaneous injections of apomorphine]. Medicina (B Aires) 1995, 55, 1, 5-10. 
80. Ostergaard L, Werdelin L, Odin P, Lindvall, O.; Dupont E. et al. Pen injected apomorphine against off phenomena in late Parkinson's disease: a double blind, placebo controlled study. J Neurol Neurosurg Psychiatry 1995, 58, 6, 681-687. https://doi.org/10.1136/jnnp.58.6.681

81. Esteban Munoz, J.; Marti, M. J.; Marin, C.; Tolosa, E. Long-term treatment with intermitent intranasal or subcutaneous apormorphine in patients with levodopa-related motor fluctuations. Clin Neuropharmacol 1997, 20, 3, 245-252. https://doi.org/10.1097/00002826-199706000-00009

82. Pietz, K.; Hagell, P.; Odin, P. Subcutaneous apomorphine in late stage Parkinson's disease: a long term follow up. J Neurol Neurosurg Psychiatry 1998, 65, 5, 709-716. https://doi.org/10.1136/jnnp.65.5.709

83. Dewey, R. B. Jr; Hutton, J. T.; LeWitt, P. A.; Factor, S. A. A randomized, double-blind, placebocontrolled trial of subcutaneously injected apomorphine for parkinsonian off-state events. Arch Neurol 2001, 58, 9, 1385-1392. https://doi.org/10.1001/archneur.58.9.1385

84. Fahn, S.; Elton, R. UPDRS program members. Unified Parkinson's Disease Rating Scale. In: Recent developments in Parkinsons disease. Fahn, S.; Marsden, C. D.; Goldstein, M.; Calne, D. B. Eds., Macmillan Healthcare Information, Florham Park, NJ: USA, 1987; pp. 153-63

85. Pfeiffer, R. F.; Gutmann, L.; Hull, K. L. Jr. et al. Investigators APOS. Continued efficacy and safety of subcutaneous apomorphine in patients with advanced Parkinson's disease. The role of subcutaneous infusion of apomorphine in PD. Review. Parkinsonism Relat Disord 2007, 13, 2, 93100.

86. Stacy, M. Apomorphine: north American clinical experience. Neurology 2004, 62, 6, 4, S18-21. https://doi.org/10.1212/wnl.62.6_suppl_4.s18

87. Pahwa, R.; Koller, W. C.; Trosch, R. M.; et al. Subcutaneous apomorphine in patients with advanced Parkinson's disease: a dose-escalation study with randomized, double-blind, placebocontrolled crossover evaluation of a single dose. J Neurol Sci 2007, 258, 1-2, 137-143. https://doi.org/10.1016/j.jns.2007.03.013

88. Trosch, R. M.; Silver, D; Bottini, P. B. Intermittent subcutaneous apomorphine therapy for 'off' episodes in Parkinson's disease: a 6-month open-label study. CNS Drugs 2008, 22, 6, 519-527. https://doi.org/10.2165/00023210-200822060-00005

89. Isaacson, S. H.; Chaudhuri, K. R. Morning akinesia and the potential role of gastroparesis managing delayed onset of first daily dose of oral levodopa in patients with Parkinson's disease. Eur Neurol Rev 2013, 8, 2, 82-84. https://doi.org/10.17925/ENR.2013.08.02.82

90. Katzenschlager, R.; Poewe, W.; Rascol, O.; Trenkwalder, C; Deuschl, G. et al. Apomorphine subcutaneous infusion in patients with Parkinson's disease with persistent motor fluctuations (TOLEDO): a multicentre, double-blind, randomised, placebo-controlled trial. Lancet Neurol 2018, 17, 9, 749-759. http://dx.doi.org/10.1016/S1474-4422(18)30239-4

91. Nyholm, D.; Lennernas, H. Irregular gastrointestinal drug absorption in Parkinson's disease. Expert Opin Drug Metab Toxicol 2008, 4, 193-203. https://doi.org/10.1517/17425255.4.2.193

92. Pahwa, R.; Lyons, K. E. Handbook of Parkinson's Disease, 5th ed. CRC Press: Boca Raton, FL, 2013; p. 51

93. Rizos, A.; Martinez-Martin, P.; Odin, P.; Antonini, A.; Kessel, B. et al. Characterizing motor and nonmotor aspects of early-morning off periods in Parkinson's disease: an international multicenter study. Parkinsonism Relat Disord 2014, 20, 1231-1235. https://doi.org/10.1016/j.parkreldis.2014.09.013

94. Hauser, R. A.; Isaacson, S.; Clinch, T. The Tigan/Apokyn Study: randomized, placebo-controlled trial of trimethobenzamide to control nausea and vomiting during initiation and continued treatment with subcutaneous apomorphine injection. Parkinsonism Relat Disord 2014, 20, 11711176. https://doi.org/10.1016/j.parkreldis.2014.08.010

95. Goetz, C. G.; Tilley, B. C.; Shaftman, S. R.; Stebbins, G. T.; Fahn, S. et al. Movement Disorder Society-sponsored revision of the Unified Parkinson's Disease Rating Scale (MDS-UPDRS): scale presentation and clinimetric testing results. Mov Disord 2008, 23, 2129-70.

https://doi.org/10.1002/mds.22340 
96. Schlachetzki, J. C. M.; Barth, J.; Marxreiter, F.; Gossler, Ju.; Kohl, Z. et al (2017) Wearable sensors objectively measure gait parameters in Parkinson's disease. PLoS One 2017, 12, e0183989e0183918. https://doi.org/10.1371/ journal.pone.0183989

97. Gancher, S. T.; Bennett, W.; English, J.; Studies of renal function in animals chronically treated with apomorphine. Res Commun Chem Pathol Pharmacol 1989, 66, 163-166.

98. LeWitt, P. A. Subcutaneously administered apomorphine: pharmacokinetics and metabolism. Neurology 2004, 62, S8-S11. https://doi.org/10.1212/wnl.62.6_suppl_4.s8

99. van Laar, T.; Jansen, E. N.; Essink, A. W.; Neef, C.; Oosterloo, S. et al. R.A. Roos, A doubleblind study of the efficacy of apomorphine and its assessment in 'off'-periods in Parkinson's disease. Clin Neurol Neurosurg 1993, 95, 231-235. https://doi.org/10.1016/0303-8467(93)90128-4

100.Ostergaard, L.; Werdelin, L.; Odin, P.; Lindvall, O.; Dupont, E. et al., Pen injected apomorphine against off phenomena in late Parkinson's disease: a double blind, placebo controlled study. J Neurol Neurosurg Psychiatry 1995, 58, 681-687. https://doi.org/10.1136/jnnp.58.6.681

101.Dewey Jr., R. B.; Hutton, J. T.; LeWitt, P. A.; Factor, S. A. A randomized, doubleblind, placebocontrolled trial of subcutaneously injected apomorphine for parkinsonian off-state events. Arch Neurol 2001, 58, 1385-1392. https://doi.org/10.1001/archneur.58.9.1385

102.Pfeiffer, R. F.; Gutmann, L.; Hull Jr., K.L.; Bottini, P. B.; Sherry, J. H. Continued efficacy and safety of subcutaneous apomorphine in patients with advanced Parkinson's disease. Park Rel Disord 2007, 13, 93-100. https://doi.org/10.1016/j.parkreldis.2006.06.012

103.R. Pahwa, W.C. Koller, R.M. Trosch, J.H. Sherry, Subcutaneous apomorphine in patients with advanced Parkinson's disease: a dose-escalation study with randomized, double-blind, placebocontrolled crossover evaluation of a single dose, J Neurol Sci 2007, 258, 137-143. https://doi.org/10.1016/j.jns.2007.03.013

104.Poltawski, L.; Edwards, H.; Todd, A.; Watson, T.; Lees, A.; James, C. A. Ultrasound treatment of cutaneous side-effects of infused apomorphine: a randomized controlled pilot study. Mov Disord 2009, 24, 115-118. https://doi.org/10.1002/mds.22316

105.Hughes, A. J.; Lees, A. J.; Stern, G. M. The motor response to sequential apomorphine in parkinsonian fluctuations. J Neurol Neurosurg Psychiatry 1991, 54, 4, 358-360. https://doi.org/10.1136/jnnp.54.4.358

106.Hagell, P.; Odin, P. Apomorphine in Parkinson's disease, 3rd ed. UNI-MED: Bremen, 2014; p.95

107.Hughes, A. J.; Lees, A. J.; Stern, G. M. Apomorphine test to predict dopaminergic responsiveness in parkinsonian syndromes. Lancet 1990,336, 8706, 32-34. https://doi.org/10.1016/01406736(90)91531-E

108.Hughes, A. J.; Lees, A. J.; Stern, G. M. Apomorphine in the diagnosis and treatment of parkinsonian tremor. Clin Neuropharmacol 1990, 13, 4, 312-317. https://doi.org/10.1097/00002826199008000-00005

109.Frankel, J. P.; Lees, A. J.; Kempster, P. A.; Stern, G. M. Subcutaneous apomorphine in the treatment of Parkinson's disease. J Neurol Neurosurg Psychiatry 1990, 53, 2, 96-101. https://doi.org/10.1136/jnnp.53.2.96

110.Djamshidian, A.; Poewe, W. Apomorphine and levodopa in Parkinson's disease: two revolutionary drugs from the 1950's. Parkinsonism Relat Disord 2016, 33, 1, S9-12. https://doi.org/10.1016/j.parkreldis.2016.12.004

111.Henriksen, T. Clinical insights into use of apomorphine in Parkinson's disease: tools for clinicians. Neurodegener Dis Manag 2014, 4, 3, 271-282. https://doi.org/10.2217/nmt.14.17

112.Hughes, A. J.; Bishop, S.; Lees, A. J; Stern, G. M.; Webster, R.; Bovingdon, M. Rectal apomorphine in Parkinson's disease. Lancet 1991, 337, 8733, 118. https://doi.org/10.1016/0140-6736(91)90780-S

113.Kleedorfer, B.; Turjanski, N.; Ryan, R.; Lees, A. J.; Milroy, C.; Stern, G. M. Intranasal apomorphine in Parkinson's disease. Neurology 1991, 41, 5, 761-762. https://doi.org/10.1212/WNL.41.5.761-a

114.Hughes, A. J.; Webster, R.; Bovingdon, M.; Lees, A. J.; Stern, G. M. Sublingual apomorphine in the treatment of Parkinson's disease complicated by motor fluctuations. Clin Neuropharmacol 1991, 14, 6, 556-561. https://doi.org/10.1097/00002826-199112000-00008 
115.Manson, A. J.; Hanagasi, H.; Turner, K.; Patsalos, P. N.; Carey, P. et al. Intravenous apomorphine therapy in Parkinson's disease: clinical and pharmacokinetic observations. Brain 2001, 124, 2, 331340. https://doi.org/10.1093/brain/124.2.331

116. Obering, C. D.; Chen, J. J.; Swope, D. M. Update on apomorphine for the rapid treatment of hypomobility ("off") episodes in Parkinson's disease. Pharmacotherapy 2006, 26, 6, 840-52. https://doi.org/10.1592/phco.26.6.840

117.Hughes, A. J.; Bishop, S.; Kleedorfer, B.; Turjanski, N.; Fernandez, W. et al. Subcutaneous apomorphine in Parkinson's disease: response to chronic administration for up to five years. Mov Disord 1993, 8, 2, 165-170. https://doi.org/10.1002/mds.870080208

118.Colosimo, C.; Merello, M.; Hughes, A. J.; Sieradzan, K.; Lees, A. J. Motor response to acute dopaminergic challenge with apomorphine and levodopa in Parkinson's disease: implications for the pathogenesis of the on-off phenomenon. J Neurol Neurosurg Psychiatry 1996, 60, 6, 634-637. https://doi.org/10.1136/jnnp.60.6.634

119.Gunzler, S. A. Apomorphine in the treatment of Parkinson disease and other movement disorders. Expert Opin Pharmacother 2009, 10, 6, 1027-1038. https://doi.org/10.1517/14656560902828344

120.Ondo, W. G.; Hunter, C.; Ferrara, J. M.; Mostile, G. Apomorphine injections: predictors of initial common adverse events and long term tolerability. Parkinsonism Relat Disord 2012, 18, 5, 619-622. https://doi.org/10.1016/j.parkreldis.2012.01.001

121.Kapoor, R.; Turjanski, N.; Frankel, J.; Kleedorfer, B.; Lees, A. et al. Intranasal apomorphine: a new treatment in Parkinson's disease. J Neurol Neurosurg Psychiatry 1990, 53, 11, p.1015. https://doi.org/10.1136/jnnp.53.11.1015

122.Melamed, E.; Offen, D.; Shirvan, A.; Ziv, I. Levodopa - on exotoxin or a therapeutic drug? J Neurol 2000, 247, 2, 135-139. https://doi.org/10.1007/p100022914

123.Katunina, E.; Titova, N. The Epidemiology of Nonmotor Symptoms in Parkinson's Disease (Cohort and Other Studies). Int Rev Neurobiol 2017, 133, 91-110. https://doi.org/10.1016/bs.irn.2017.05.012

124.Borgemeester, R. W. K.; Lees, A. J.; van Laar, T. Parkinson's disease, visual hallucinations and apomorphine: a review of the available evidence. Park Relat Disord 2016, 27, 35-40. https://doi.org/10.1016/j.parkreldis.2016.04.023

125.Rosa-Grilo, M.; Qamar, M. A.; Evans, A.; Chaudhuri, K. R. The efcacy of apomorphine-a nonmotor perspective. Park Relat Disord 2016, 33, S28-35. https://doi.org/10.1016/j.parkreldis.2016.11.020

126.Moore, T. J.; Glenmullen, J.; Mattison, D. R. Reports of pathological gambling, hypersexuality, and compulsive shopping associated with dopamine receptor agonist drugs. JAMA Intern Med 2014, 174, 12, p. 1930. https://doi.org/10.1001/jamainternmed.2014.5262

127.Barbosa, P.; Lees, A. J.; Magee, C.; Djamshidian, A.; Warner, T. T. A retrospective evaluation of the frequency of impulsive compulsive behaviors in parkinson's disease patients treated with continuous waking day apomorphine pumps. Mov Disord Clin Pract 2016, 4, 3, 323-328. https://doi.org/10.1002/mdc3.12416

128.Samuel, M.; Rodriguez-Oroz, M.; Antonini, A.; Brotchie, J.; Ray Chaudhuri, K. et al. Impulse control disorders in parkinson's disease: management, controversies, and potential approaches HHS public access. Mov Disord 2015, 30, 2, 150-159. https://doi.org/10.1002/mds.26099

129.Himeno, E.; Ohyagi, Y.; Ma, L.; Nakamura, N.; Miyoshi, K. et al. Apomorphine treatment in Alzheimer mice promoting amyloid- $\beta$ degradation. Ann Neurol 2011, 69, 2, 248-256. https://doi.org/10.1002/ana.22319

130.Yarnall, A. J.; Lashley, T.; Ling, H.; Lees, A. J.; Coleman, S. Y. et al. Apomorphine: a potential modifer of amyloid deposition in Parkinson's disease? Mov Disord 2016, 31, 5, 668-675. https://doi.org/10.1002/mds.26422

131.Fahn, S.; Oakes, D.; Shoulson, I.; Kieburtz, K.; Rudolph, A. et al. Levodopa and the progression of Parkinson's disease. N Engl J Med 2004, 351, 2498-2508. https://doi.org/10.1056/nejmoa033447 
132.Martinez-Martin, P.; Reddy, P.; Katzenschlager, R.; Antonini, A.; Todorova, A. et al. EuroInf: a multicenter comparative observational study of apomorphine and levodopa infusion in Parkinson's disease. Mov Disord 2015, 30, 510-516. https://doi.org/10.1002/mds.26067

133.Trenkwalder, C.; Ray Chaudhuri, K.; Ruiz, P. J. G.; LeWitt, P.; Katzenschlager, R. et al. Expert Consensus Group report on the use of apomorphine in the treatment of Parkinson's disease -Clinical practice recommendations. Parkinsonism Relat Disord 2015, 21, 9, 1023-1030. https://doi.org/10.1016/j.parkreldis.2015.06.012

134.Cotzias, G. C.; Papavasilliou, P. S.; Fehling, C.; Kaufman, B.; Mena, I. Similarities between neurologic effects of L- dopa and of Apomorphine. N Engl J Med 1970, 282, 1, 31-33. https://doi.org/10.1056/nejm197001012820107 